\title{
Review Article \\ Polycystic Ovary Syndrome: Effect and Mechanisms of Acupuncture for Ovulation Induction
}

\author{
Julia Johansson $^{1}$ and Elisabet Stener-Victorin ${ }^{1,2}$ \\ ${ }^{1}$ Institute of Neuroscience and Physiology, Department of Physiology, Sahlgrenska Academy, \\ University of Gothenburg, Box 434, 40530 Gothenburg, Sweden \\ ${ }^{2}$ Department of Obstetrics and Gynecology, First Affiliated Hospital, Heilongjiang University of Chinese Medicine, \\ Harbin 150040, China \\ Correspondence should be addressed to Elisabet Stener-Victorin; elisabet.stener-victorin@neuro.gu.se
}

Received 29 April 2013; Accepted 23 July 2013

Academic Editor: Ernest Hung Yu Ng

Copyright (C) 2013 J. Johansson and E. Stener-Victorin. This is an open access article distributed under the Creative Commons Attribution License, which permits unrestricted use, distribution, and reproduction in any medium, provided the original work is properly cited.

\begin{abstract}
Polycystic ovary syndrome (PCOS), the most common endocrine disorder among women of reproductive age, is characterized by the coexistence of hyperandrogenism, ovulatory dysfunction, and polycystic ovaries (PCO). PCOS also represents the largest part of female oligoovulatory infertility, and the management of ovulatory and menstrual dysfunction, comprises a third of the high costs of PCOS treatment. Current pharmacological and surgical treatments for reproductive symptoms are effective, however, associated with negative side effects, such as cardiovascular complications and multiple pregnancies. For menstrual irregularities and ovulation induction in women with PCOS, acupuncture has indicated beneficial effects. This review will focus on the results from randomized controlled acupuncture trials for regulation of menstrual dysfunction and for inducing ovulation in women with PCOS although there are uncontrolled trials with nonetheless interesting results. Animal experimental studies will be further discussed when they can provide a more mechanistic explanatory view.
\end{abstract}

\section{Introduction}

Although polycystic ovary syndrome (PCOS) has been recognized for more than 70 years there is no cohesive definition, and the diagnosis still causes debate. The most recent and used definitions are the National Institute of Health (NIH), Rotterdam, and Androgen excess and PCOS society (AES) criteria, where all are presently used in clinic (Table 1). In consequence, prevalence is difficult to conclude and depends on the used definition, as well as the ethnicity of the measured population. Most studies report prevalence between 6-15\% but sometimes even up to $20 \%$, depending on used criteria [1-3]. The different definitions also result in several PCOS phenotypes with a wide range of severity of the syndrome (Table 1), which comprises concerns when comparing clinical studies using different definitions. A recent NIH workshop on PCOS recommended to explicitly report PCOS phenotypes in all future clinical studies $[4,5]$.

\section{Pathophysiology and Etiology of PCOS}

Despite high incidence, the etiology of PCOS remains unknown. Due to the heterogeneity in the representation of clinical and biochemical features, it has been debated whether PCOS actually represents one single disorder or several ones. Symptoms of PCOS often manifest around puberty, but the origin may be programmed already as early as during fetal development [6-8]. One of the most common features of PCOS is insulin resistance, represented in $85 \%$ of PCOS women [9]. The other common feature of PCOS, elevated androgen levels, affects around $60-80 \%$ of PCOS women and can result in the clinical signs: hirsutism, acne, and, to some extent, alopecia [10]. In PCOS, high circulating levels of androgens, estrogens, sex steroid precursors, and glucuronidated androgen metabolites have been demonstrated by gas chromatography tandem mass spectrometry (GC-MS/ MS) and liquid chromatography tandem mass spectrometry 
TABle 1: Diagnostic criteria of PCOS.

\begin{tabular}{|c|c|c|c|}
\hline Diagnostic criteria & NIH 1990 & Rotterdam 2003 & AES 2006 \\
\hline & Require & At least two out of & Require \\
\hline Hyperandrogenism $(\mathrm{HA})^{\mathrm{A}}$ & $\sqrt{ }$ & $\sqrt{ }$ & $\sqrt{ }$ \\
\hline Ovulatory dysfunction $(\mathrm{OD})^{\mathrm{B}}$ & $\sqrt{ }$ & $\sqrt{ }$ & and/or $\sqrt{ }$ \\
\hline PCO morphology $(\mathrm{PCO})^{\mathrm{C}}$ & & $\sqrt{ }$ & and/or $\sqrt{ }$ \\
\hline Possible phenotypes & (1) $\mathrm{HA}+\mathrm{OD}$ & $\begin{array}{l}\text { (1) } \mathrm{HA}+\mathrm{OD}+\mathrm{PCO} \\
\text { (2) } \mathrm{HA}+\mathrm{OD} \\
\text { (3) } \mathrm{HA}+\mathrm{PCO} \\
\text { (4) } \mathrm{PCO}+\mathrm{OD}\end{array}$ & $\begin{array}{c}\text { (1) } \mathrm{HA}+\mathrm{OD}+\mathrm{PCO} \\
\text { (2) } \mathrm{HA}+\mathrm{OD} \\
\text { (3) } \mathrm{HA}+\mathrm{PCO}\end{array}$ \\
\hline
\end{tabular}

\footnotetext{
${ }^{\mathrm{A}}$ Clinical or biochemical signs of hyperandrogenism.

${ }^{\mathrm{B}}$ Oligomennorrhea, amenorrhea, oligoovulation, or anovulation.

${ }^{C} \geq 12$ follicles of $2-9 \mathrm{~mm}$ and/or enlarged ovarian volume of $\geq 10 \mathrm{~mL}$ in one or both ovaries.
}

(LC-MS/MS) [11]. The major androgen excess in PCOS originates from the ovaries, but the adrenals also contribute to some part [12]. Hyperinsulinemia, often found in PCOS, inhibits the production of sex hormone binding globulin (SHBG), thereby further contributing to levels of free circulating androgens [13]. Figure 1 summarizes the PCOS pathophysiology described below.

Androgens possess a central position in PCOS, are closely related to the ovarian morphology, and are sufficient to cause PCOS-like states in both animal models and femaleto-male transsexuals $[14,15]$. Both androgens and insulin have therefore been presented as a key underlying cause of PCOS. Since it is not known when or where the pathology actually begins, several different hypotheses are presented. Prenatal androgenization represents an established hypothesis of PCOS etiology and is based on animal models including monkeys, sheep, and rodents where prenatal androgenization inflicts several features of PCOS in the offspring [16-19]. However, in humans, although increased levels of androgens have been found in pregnant PCOS women [20], only one study has found increased levels of testosterone in umbilical vein blood in infants of PCOS mothers although these levels were measured by immunoassays and not mass spectrometry [21]. Prepubertal exposure to androgens is yet another hypothesis that originates in the pubertal start of symptom manifestation $[7,8]$, from which several animal models of PCOS have been developed [22-24].

Although it is not a part of the diagnosis, PCOS is also strongly associated with insulin resistance and compensatory hyperinsulinemia, type 2 diabetes, and dyslipidemia [25, 26] and the prevalence of women with PCOS being either overweight or obese is high [27]. Both androgens and insulin, which both increase during puberty, are therefore considered to be two key players in PCOS. Most likely both contribute, but it is still unclear which one of these that is most related to the etiology $[7,8]$.

Asides from these genetics, altered ovarian steroidogenesis $[28,29]$, and increased sympathetic activity [30] has been proposed as participating causative mechanisms.

2.1. Neuroendocrine Dysfunction in PCOS. In PCOS the disturbed hypothalamic-pituitary-ovarian (HPO) axis has been extensively reviewed [31-34]. The most evident neuroendocrine feature regulating abnormal ovarian follicle development in PCOS is increased luteinizing hormone (LH) pulsatility regarding both frequency and amplitude, with relatively low FSH secretion [35-39]. Increased LH pulse frequency increases theca cell production of androgens, while the lower FSH levels impairs follicle maturation and consequently ovulation [32].

The cause of LH hypersecretion in PCOS is probably due to enhanced pituitary sensitivity to gonadotropin releasing hormone $(\mathrm{GnRH})$ or to changes in $\mathrm{GnRH}$ secretion patterns rather than increased GnRH secretion [35, 39, 40]. It appears to be a result of an acquired impaired sensitivity of the hypothalamic pulse generator to the negative feedback of estrogen and progesterone in PCOS, possibly by chronic estrogen exposure [35, 38, 39, 41]. Levels of follicle stimulating hormone (FSH) in PCOS appear to be low or within the lower follicular range, and response to $\mathrm{GnRH}$ is relatively similar to ovulatory controls [35]. Altered sex steroid production, metabolic dysfunction, and obesity may all contribute to the changes in LH secretion pattern. Hyperandrogenemia itself may cause hypothalamic desensitization to progesterone/estrogen negative feedback that further increase gonadotropin secretion and hence ovarian androgen production, causing a self-driven viscous circle $[42,43]$. Although increased body mass index (BMI) has a blunting effect on LH secretion [36, 39], hyperinsulinemia and insulin resistance may directly or indirectly (by enhancing ovarian gonadotropin stimulated sex steroid production) contribute to the abnormal gonadotropin secretion, although the mechanism is not clear [44-46]. All these factors increase free androgen levels and contribute to anovulation.

2.2. Ovarian Dysfunction in PCOS. The ovulatory dysfunction in PCOS can be ascribed to disturbed follicular development with excessive early follicular growth and abnormal later stages of arrested follicle growth well before expected maturation [47]. This pattern of follicular growth with failure in the selection of a dominant follicle for ovulation results in one of the hallmarks of PCOS, PCO morphology. The ovarian dysfunction of PCOS involves both these morphological features of polycystic ovaries, described as an accumulation 


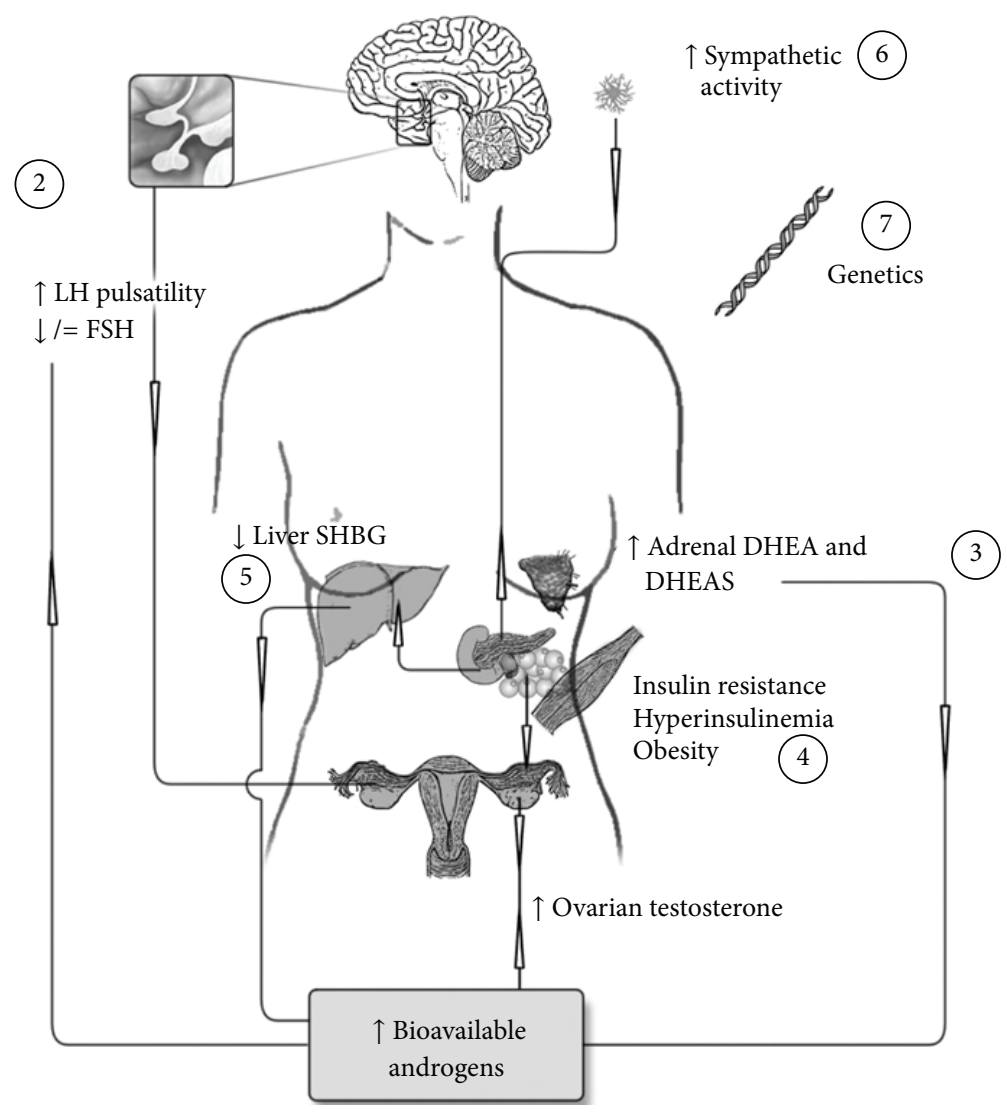

FIGURE 1: Summary of the PCOS pathophysiology. (1) Ovarian androgens are the main source of hyperandrogenemia in PCOS. Hyperandrogenemia has both a direct effect on the ovarian alterations and (2) an increasing effect on pituitary LH pulse frequency and amplitude with relative low FSH secretion. (3) Further, adrenal androgens contribute to PCOS androgen excess. (4) Insulin resistance with compensatory hyperinsulinemia enhances ovarian androgen production as well as (5) decreases production of SHBG in the liver, and both increase the pool of bioavailable androgens. (6) PCOS is also associated with increased muscle sympathetic nerve activity that is related to high testosterone, insulin resistance, and obesity. (7) Genetic defects probably contribute to the pathology of PCOS. LH: luteinizing hormone, FSH: follicle stimulating hormone, SHBG: sex hormone binding globulin, DHEA: dehydroepiandrosterone, and DHEAS: dehydroepiandrosterone sulphate.

of small antral follicles of size $2-9 \mathrm{~mm}$, as well as the clinical consequence of oligo-/anovulation. The prevalence of menstrual irregularities oligo-/amenorrhea in PCOS depends on the used diagnostic criteria but is approximately $75 \%$ [10]. If we use the NIH criteria, of course all patients will experience menstrual irregularities. Ultimately, irregular ovulation can cause infertility due to difficulties conceiving and should be acknowledged.

Moreover, there are several other follicle abnormalities where the most consistent feature is androgen hypersecretion [48]. Ovarian steroid production is based on a close collaboration between theca and granulosa cells in the growing follicles and requires gonadotropin input (Figure 2) [49]. Theca cells produce androstenedione from cholesterol, either by the $\Delta 4$ or $\Delta 5$ pathway, and the conversion to estrone and estradiol thereafter is exclusively acknowledged aromatase cytochrome P450 hydroxylase (CYP19) containing granulosa cells [50]. Women with PCOS appear to have theca interna hyperplasia, a thicker layer of the theca cells, which seem to be responsible for their increased androgen steroidogenesis.
Moreover, each theca cell has increased expression of $\mathrm{LH}$ receptors, with increased susceptibility to LH stimulation $[33,50,51]$.

There are local selectors for follicle recruitment and growth within the ovary that might contribute to the impaired follicle development in PCOS. AMH is expressed by early antral and preantral follicles, but not in later stages of development, and reflects the size and activity of the follicular pool $[52,53]$. There is also evidence of its involvement in the regulation of recruitment of primordial follicles into the growing pool, presumably by decreasing the granulosa cell sensitivity to FSH [54]. Adding antimüllerian hormone $(\mathrm{AMH})$ to ovarian cultures reduces the number of growing follicles, while removing the gene increased the proportion $[55,56]$. In the small primordial and transitional follicles of anovulatory PCOS, AMH protein expression is reported to be reduced [57]. This may contribute to the inappropriate recruitment of growing follicles. Additionally in both circulation and antral follicular fluid of PCOS women, $\mathrm{AMH}$ levels are increased, and these are associated with poor 


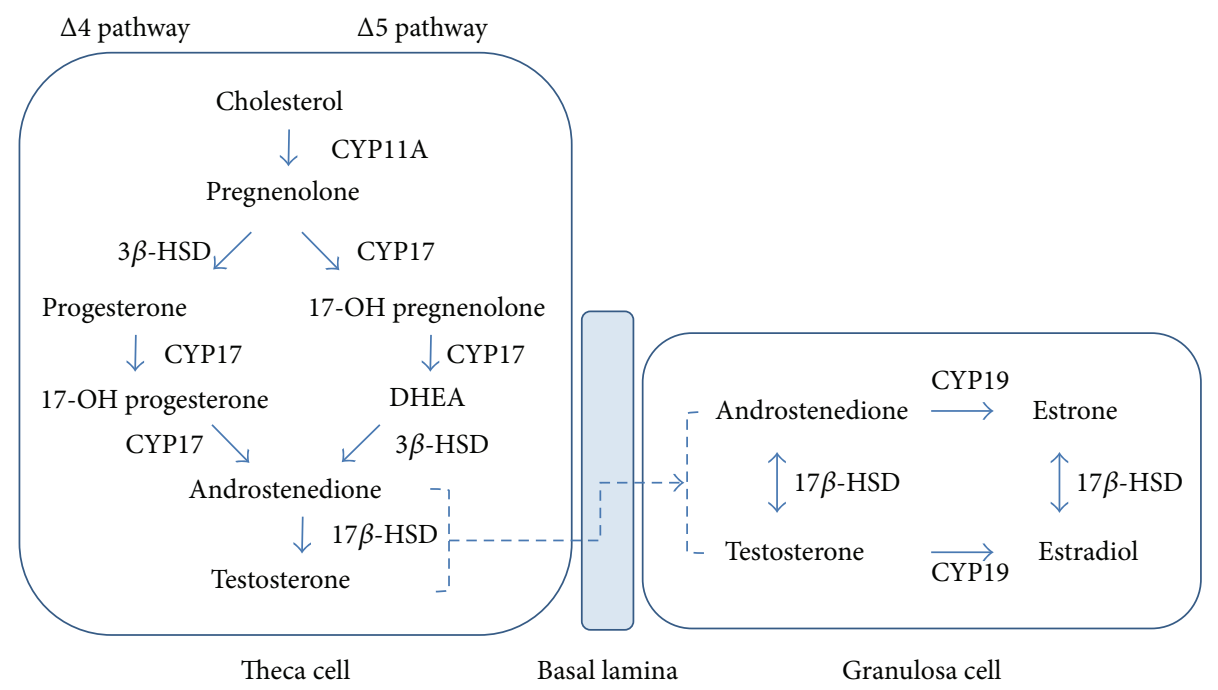

FIGURE 2: Schematic illustration of steroid synthesis in the ovary.

reproductive responsiveness to treatment [58-63]. These high circulating levels may be a reflection of the increased pool of granulosa cells instead of an increased expression. Since high levels of AMH are associated with lower levels of FSH and estradiol, it has been suggested that the AMH excess is involved in the lack of FSH-induced aromatase activity that is characteristic of follicular arrest in PCOS $[62,64]$. In addition, testosterone exposure downregulates $\mathrm{AMH}$ expression in granulosa cells of small bovine follicles in culture and could possibly represent a mechanistic origin of PCOS [65].

Ovarian inhibins are expressed in ovaries and act as modulators to suppress FSH levels. As a response to increased FSH levels inhibin B is increasingly expressed during early follicular phase in small developing follicles, while inhibin $\mathrm{A}$ is selectively produced in the dominant follicle. Inhibin $\mathrm{B}$ therefore correlates to total follicle number and may be a marker of follicle quality [66]. But inhibins also have a local effect to stimulate androgen production synthesis in theca cells for estradiol production [66-68]. Most PCOS studies find no differences in basal circulating inhibin $\mathrm{B}$, but an abnormal and increased response to FSH. The normal basal levels may be explained by the diminished FSH secretion in PCOS or that the follicle quality is lower. The increased response to FSH could simply be due to their increased number of preantral and small antral follicles [67-70]. Moreover, follicular arrest in PCOS is associated with reduced levels of both inhibin A and inhibin B in follicular fluid, which both could explain the normal circulating levels although their increased pool of growing follicles, but also making these to possible actors in the impaired follicle development [71]. There is low evidence of any diagnostic value of circulating basal inhibin B measurements in PCOS $[67,72]$.

Taken together, impaired folliculogenesis and steroidogenesis in PCOS seem to be multifactorial and are probably influenced by extra ovarian factors such as androgens, insulin, neuroendocrine alterations, and intraovarian local and intrinsic factors.
2.3. Increased Sympathetic Activity. The autonomic nervous system consists of two divisions: the sympathetic and the parasympathetic nervous systems, and is controlled by the neurotransmitters noradrenaline and adrenaline and activation of adrenergic receptors. In a normal, healthy state, a fine balance between these two divisions, ensures homeostasis. Many of the classical components of PCOS such as polycystic ovaries, insulin resistance with related hyperinsulinemia, central obesity, and hypertension are associated with increased sympathetic activity [73-76]. It has therefore been suggested to account for at least a part of the syndrome etiology $[74,75,77]$. That increased sympathetic innervation of the ovaries might contribute to the impaired follicular development in PCOS that is supported by clinical evidence such as increased density catecholaminergic nerve fibers, increased NGF production, and altered catecholamine metabolism and/or uptake in PCOS ovaries [75, 78, 79]. Heart-rate recovery after a bout of exercise and heart-rate variability can be used as noninvasive markers of autonomic function. Measures in PCOS women indicate that they have decreased dynamic activity in their autonomic function, possibly by decreased activity in the parasympathetic component and increased in the sympathetic component [8083]. These are though indirect measures and their accuracy may be questionable. We have though demonstrated by microneurography, which is a direct and reliable measure of muscle sympathetic nerve activity (MSNA), that women with PCOS have an increased sympathetic nerve activity that is correlated to high levels of testosterone [30].

\section{PCOS: A Well-Orchestrated Pathology}

Androgens play a central part in the pathology of PCOS. Androgens alone can affect many of the systems that are impaired in the syndrome and are sufficient to cause PCOSlike states in both animal models and female-to-male transsexuals $[14,15,17-19,84-86]$. But these alterations 
can themselves further increase hyperandrogenemia. Consequently, a vicious circle is created where the individual pieces may augment each other, although it is not clear where it started. Hyperandrogenemia in PCOS originates mainly from the ovaries and can have central effects by increasing gonadotropin secretion via affecting sex-steroid feed-back systems as well as enhancing the effect on ovarian gonadotropin stimulated sex steroid production [12, 42, 43]. Androgens also directly impair follicle development and maturation and thereby contribute both to the PCO morphology and to the ovarian pool of androgen producing cells [12]. Both of these will further drive ovarian androgen production and increase levels of free circulating androgens. Additionally, although the mechanism is not completely clear, increased adrenal androgen production contributes to the androgen excess in PCOS $[87,88]$.

Androgens are also associated with an atherogenic blood lipid profile, enlarged adipocyte size, and peripheral insulin resistance although the androgen excess may not be the primary cause of their insulin resistance [89-91]. Moreover, together with obesity, this increases the risk of type 2 diabetes and cardiovascular disease (CVD) [27]. Similar to androgens, insulin resistance and hyperinsulinemia enhance ovarian gonadotropin stimulated sex steroid production [12, 44-46] and may contribute to the abnormal gonadotropin secretion although the mechanism is not clear [44-46]. Hyperinsulinemia also decreases liver production of sex hormone binding globuline (SHBG) which increases the amount of bioavailable free circulating sex steroids [13].

PCOS is related to increased MSNA and of special interest is that testosterone concentration was found to be a strong independent predictor [30]. Increased sympathetic nerve activity is related to insulin resistance with related hyperinsulinemia, central obesity, and hypertension [73-76] and might contribute to the increased cardiovascular risk [30]. There is also evidence that supports an increased sympathetic nerve activity to the ovaries $[75,78,79,92]$ that may further drive androgen production and PCO morphology [93]. Apart from the previously described factors, there is a strong genetic component with familial aggregation of cases and symptoms $[94,95]$ that probably is involved in the etiology of PCOS. Altogether, PCOS is a coordinated pathology containing factors that strongly influence each other in a viscous circle, making it difficult to separate the etiology.

\section{Hypothetical Mechanism of Acupuncture}

Acupuncture is widely practiced and is now also accepted in the western world for the treatment or adjunct treatment for more and more conditions [96]. It is a relatively safe treatment with few side effects [97].

Acupuncture originates from traditional Chinese medicine (TCM) where fine needles are placed in the skin and underly muscle tissue at specific areas of the body, socalled acu- or acupuncture points. When placed, needles are stimulated manually by rotating or perturbing needles up and down, so-called manual acupuncture. Needles may also be stimulated electrically by applying an electrical field and passing an electrical current between two needles, socalled electroacupuncture (EA). Low-frequency $(1-15 \mathrm{~Hz})$ electroacupuncture with an intensity that evokes muscle contractions is believed to achieve biological processes that resemble the effects of exercise. Acupuncture from a western scientific perspective cannot confirm point specificity and instead explain the effect with the activation of afferent sensory nerve fibers at appropriate segmental level [98, 99]. Acupuncture activates and modulates nervous pathways at peripheral (local), segmental (in the spinal cord), and supraspinal levels within central nervous system (CNS). Figure 3 illustrates the hypothetical mechanism explaining the effects of acupuncture in PCOS.

Starting at a peripheral level, both manual and electrical stimulations increase glucose uptake and microcirculation [100-103]. When needles are inserted and stimulated, peripheral nerve terminals release several neuropeptides, such as neuropeptide Y (NPY), vasoactive intestinal polypeptide (VIP), substance $\mathrm{P}$, and calcitonin gene-related peptide (CGRP), and give an immediate local reaction, by which the two latter are probably involved, with an increase in microcirculation $[100,104,105]$. Moreover, data from administration of the opioid antagonist naloxone also suggest low-frequency EA stimulated peripheral opioid release [106].

Mechanoreceptors, responding to mechanic pressure or distortion, are activated by muscle contractions and are suggested to be involved in the somatic response of both manual and electrical stimulations [107, 108]. Activation of mechanoreceptors by manual or electrical stimulation activates sensory nerve fibers, myelinated $\mathrm{A} \alpha, \beta, \delta$, and unmyelinated C-fibers $[109,110]$. These signals are transmitted to the spinal cord (segmental level) where they through spinal reflexes may modulate the sympathetic output to the target organs in the same area of innervation as where needles are placed [111]. Importantly, these signals are also controlled via supraspinal pathways within the central nervous system (CNS) [112].

The efficacy of acupuncture for analgesia has been extensively studied and widely used. The involvement of endogenous opioids within the central nervous system has been suggested to mediate the effect of acupuncture-induced analgesia and lowering of blood pressure [113-116]. There are three opioid receptors $\mu, \delta$, and $\kappa$ found in peripheral afferent nerve terminals and within the central nervous system in areas related to nociception and pain $[117,118] . \beta$-endorphin, one of the cleavage products of proopiomelanocortin (POMC), binds to the $\mu$-receptor with high affinity and has received special attention [117]. $\beta$-endorphin produced in the arcuate nucleus of the medial basal hypothalamus is released within CNS, but it is also produced in the pituitary where it is released into the peripheral circulation [119-121]. The $\beta$-endorphin is produced in hypothalamus project to the midbrain (especially the periaqueductal grey) and brainstem nuclei where it can influence pain sensitivity and autonomic function $[120,121]$. The effect on autonomic function includes effects on the vasomotor centre with regulation of blood pressure and muscle sympathetic nerve activity (markers of sympathetic tone) [122]. The other system is also under hypothalamic control, by corticotrophin releasing hormone 


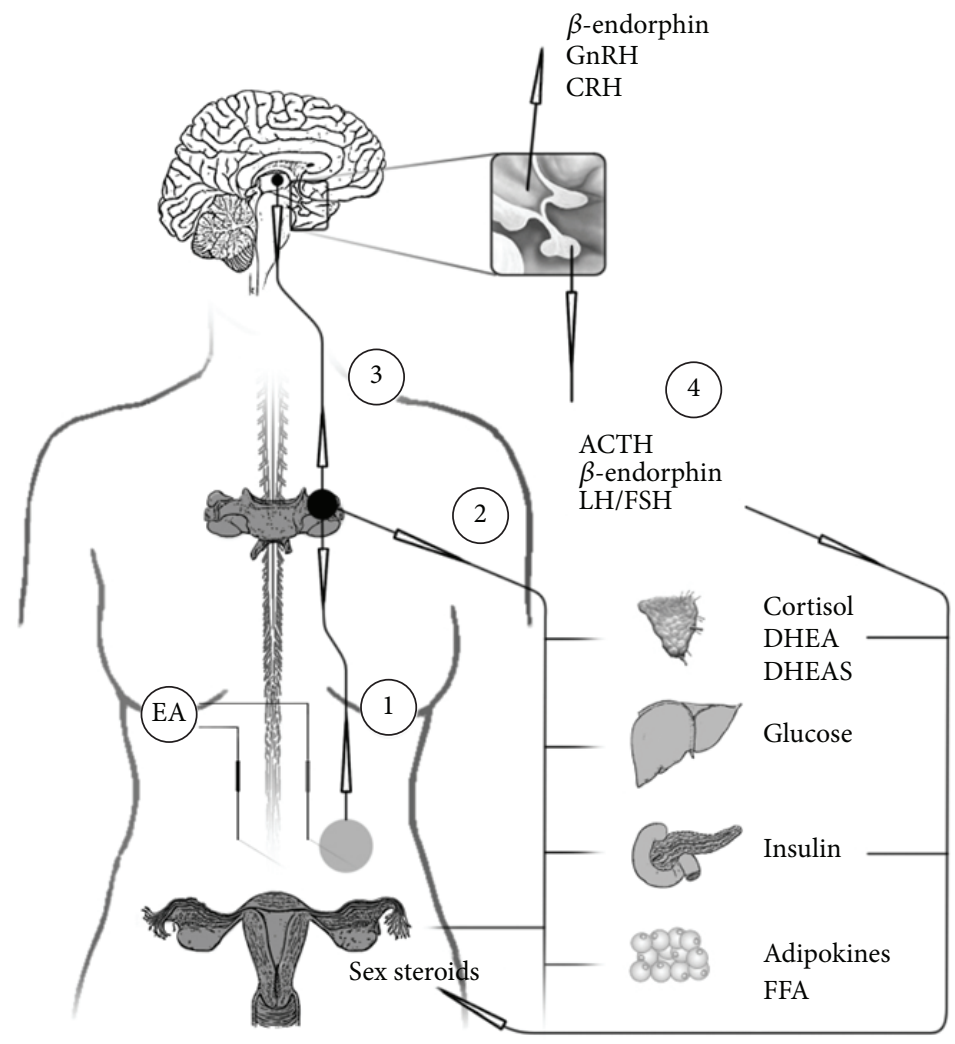

FIGURE 3: Schematic illustration of a hypothetical mechanism explaining the effects of acupuncture in PCOS. (1) Stimulation of acupuncture needles in skeletal muscle excites ergoreceptors that activate afferent sensory nerve fibers. These signals are transmitted to the spinal cord where they (2) through spinal reflexes may modulate the sympathetic output to the target organs in the same area of innervation. (3) Signals also reach the central nervous system via supraspinal pathways where they can exert central effects. Hypothalamic $\beta$-endorphin is implicated in the effect of acupuncture. It modulates the autonomic system but may also alter the release of GnRH and CRH. (4) These can enable an effect on reproductive function (via LH and FSH), adrenal function (ACTH), and pancreatic function (circulating $\beta$-endorphins). (ACTH: adrenocorticotrophic hormone, CNS: central nervous system, CRH: corticotrophin releasing hormone, EA: electroacupuncture, FFA: free fatty acids, FSH: follicle stimulating hormone, GnRH: gonadotropin releasing hormone, and LH: luteinizing hormone).

$(\mathrm{CRH})$, and involves the anterior pituitary lobe where POMC is cleaved into equal amounts of $\beta$-endorphin, melanocyte stimulating hormone, and adrenocorticotrophic hormone (ACTH) that is released into circulation [123]. The two systems work independently, but both can be activated by afferent nerve activity such as manual and low-frequency electrical stimulation of acupuncture needles and exercise [120].

The $\beta$-endorphinergic system is involved in many physiological effects, both centrally and peripherally, such as reproductive function, analgesia, stress response, and carbohydrate metabolism [124]. Both circulating and central levels of $\beta$-endorphin have been shown to be modulated by acupuncture [125-127]. Further implications of acupuncture involving modulation of autonomic function are the reducing effect on MSNA and blood pressure $[128,129]$. The pain reliving effect of acupuncture was further blocked by low doses of naloxone, an opioid receptor antagonist, and the blood pressure suppression by high doses of naloxone [129, 130].

The connection between central $\beta$-endorphin and reproductive function involves both direct and indirect tonic inhibitory effects on GnRH and subsequent $\mathrm{LH}$ release and possibly also $\mathrm{GnRH}$ biosynthesis [121, 131]. It is generally accepted that opioids mediate the inhibitory effect of estrogen [132]. Moreover, a reduction in opioid inhibitory tone amplifies and is essential, for generation of the LH surge preceding ovulation $[121,133]$.

Circulating $\beta$-endorphin is considered to be more related to stress stimuli than actually reflecting central opioid activity and should not be used as a marker of central activity [134]. Still, the changes in plasma $\beta$-endorphin provide a link to the hypothalamus pituitary (HPA) axis, since $\beta$-endorphin is coreleased with ACTH from the pituitary [123]. The controlling factor $\mathrm{CRH}$ is released by stress, but it is also known to decrease GnRH secretion, linking it back to the reproductive axis [135]. Acupuncture has been shown to decrease levels of $\mathrm{CRH}$ within hypothalamus and may therefore present effects on both HPO and HPA axes [136].

4.1. Control Situations of Acupuncture? In general the effect of acupuncture may also be influenced by the patient's own expectations, since there is a strong psychological component 
to it [137]. The use of placebo in acupuncture experiments is therefore always under debate, and efforts to develop suitable control situations have been made. However, the use of socalled placebo needles or minimal/sham acupuncture may not be a true control since clinical studies suggest that they are not inert treatments $[138,139]$.

4.2. Implications of Acupuncture for Ovulation Induction in PCOS. Since many of the features of PCOS are associated with disturbed opioid or sympathetic tone, including disturbed gonadotropin secretion, insulin resistance, and central obesity [74, 124], opioid and/or sympathetic tone may be implicated in the pathogenesis of the condition. Women with PCOS have higher levels of circulating $\beta$-endorphin which may contribute to the pathogenesis, possibly by insufficient inhibition of GnRH by $\beta$-endorphins in the CNS $[124,140-$ 142]. This is supported by studies in which the $\mu$-receptor antagonist naltrexone improves cyclicity and SHBG, reduces androgen levels, LH/FSH, and LH response to GnRH [143145].

The relation between acupuncture, $\beta$-endorphin, and sympathetic activity seems to be sustained also in PCOS. Acupuncture treatment has been shown to reduce both high plasma $\beta$-endorphin and sympathetic nerve activity and increase low hand-skin temperature $[30,128,146]$. The involvement of sympathetic nervous system and an alteration in neurogenic control of the ovary have been implicated in the etiology of PCOS [111, 112, 147, 148]. One hypothetical mediator for that effect, combining an autonomic and ovarian effect, is nerve growth factor (NGF). Ovarian NGF production is increased in the follicular fluid in women with PCOS and in an estradiol-valerate- (EV-) induced rat PCOS model [92, $149,150]$. Over expressing NGF in the ovaries of a transgenic mice model results in ovarian hyperinnervation, arrested follicle growth, and increased ovarian steroidal responsiveness to gonadotropins [92]. Also ovarian adrenergic receptors have been shown to be increased in the EV-induced rat PCOS model further indicating involvement of sympathetic system in the regulation of ovarian function [151]. Electroacupuncture has been shown to decrease high ovarian NGF $[149,150]$ and adrenergic receptors [152] in the EV-induced PCOS model and to decrease high mRNA expression of NGF and several markers of sympathetic activity in adipose in the DHT-induced PCOS model [153]. Together with microneurography measurements demonstrating a decrease of high MSNA in women with PCOS after 14 acupuncture treatments, this indicates an involvement of the sympathetic nervous system in both PCOS etiology and the mechanistic effect of acupuncture [30]. That naltrexone, a $\mu$-receptor that antagonist induces ovulation and decreases LH concentration, indicates also a role of $\beta$-endorphin in PCOS [143-145]. That similar effects are also mediated by electroacupuncture $[146,154,155]$ concurrent with a lowering of $\beta$-endorphin levels [146] implying the involvement of the opioid system in the underlying mechanism. This is also supported in our recent experimental study where electrical stimulation of the acupuncture needles affected the expression of opioid receptors $\mu$ and $\kappa$ in rat hypothalamus, together with improved cyclicity and reduction of circulating testosterone levels [156].

\section{Treatment of Reproductive Function in PCOS}

Due to the uncertainty of the etiology of PCOS as well as the heterogeneity of the syndrome no cure can currently be offered. Women are instead treated in a symptom-oriented manner, often for long duration, with associated adverse effects.

Lifestyle modifications, including diet and exercise, are frequently recommended as a first-line treatment in the large population of overweight and obese PCOS women. It improves several of the key features of PCOS such as body composition, hyperandrogenism, and cardiometabolic profile, including insulin sensitivity and blood lipids, but also autonomic function and inflammatory pattern [157166]. The effect may also include improved ovulatory function and pregnancy $[158,160,163,167,168]$ alone or together with clomiphene citrate (CC) [162], and even a modest (5\%) weight reduction has been reported to improve metabolic and reproductive functions [169].

For women who do not wish to conceive, combined oral contraception is frequently used for regulation of menstrual bleeding patterns and reduction of androgen levels [25]. However, use of oral contraceptives may be contraindicatory in women with PCOS suffering from obesity and/or insulin resistance or risk of cardiovascular disease [25].

Nonrandomized studies on acupuncture for women with PCOS as well as with undefined anovulation show improvements of menstruation pattern, LH/FSH ratio, estrogen, and testosterone $[146,154,155]$. The effect on ovarian function was first demonstrated in an RCT in which acupuncture with combined manual and low-frequency $(2 \mathrm{~Hz})$ electrical stimulation of needles during 30 minutes per treatment was superior to 16 weeks of exercise according to the Randeva protocol [170] and no intervention in improving menstrual frequency and lowering circulating levels of testosterone in PCOS women [166]. Needles were placed in abdominal and leg muscles in the same somatic segment as the innervation of the ovaries. The treatment period was 16 weeks and women received in total 14 treatments: twice a week during 2 weeks, once a week during 8 weeks, and thereafter every other week. Concurrently, Pastore et al. compared the effectiveness of true acupuncture and sham acupuncture using the Park device [171]. They received 12 treatments over 14 weeks and the needle placement and stimulation in the true acupuncture group followed an old protocol [172]. Both groups improved their menstrual frequency, and no difference between the groups was observed on ovulation rate during or after treatment, thus indicating that the sham device is not completely inert. In a more recent RCT, we further determined ovulation frequency in PCOS women, during a 3-month long acupuncture or attention control treatment period, by weekly progesterone measurement as well as menstrual bleeding registrations. In this study, women received acupuncture twice a week during the study period with similar needles placement as in the previous study, thus increased intensity in terms of more frequent treatment. The group who were allocated to acupuncture treatment had higher ovulation frequency compared with the attention control group [173], an effect 
that was augmented compared to the previous clinical studies on PCOS with fewer acupuncture treatments, indicating a dose-response effect $[166,171,172]$. In addition, the ovulation frequency in the attention control group [173] was comparable with ovulation frequency during CC stimulation [174], as well as the one in a previous acupuncture study on PCOS women [171]. Supporting animal data include improved ovarian morphology [153] and restored estrous cyclicity $[47,156]$ with increased progesterone levels [156] after acupuncture in a DHT-induced rat PCOS model [22]. Moreover, there were no significant differences in estrous cyclicity improvement between the two stimulation modalities: electrical and manual needle stimulations [156]. The parallel effect regarding ovulation in the rat and human studies strengthens the result by the translational nature. Proceeding to ovarian morphology in the recent RCT, no group differences were observed when counting antral follicles $\leq 9 \mathrm{~mm}$ or ovarian volume [173]. However, a tendency to reduced number of antral follicle and ovarian volume was observed within the acupuncture group [173]. This is also in line with previous animal studies where electroacupuncture improved ovarian morphology in DHT-induced PCOS rats [153]. In addition, we found reduced circulating levels of inhibin B after acupuncture, without changes in AMH [173] which was in line with a previous study [60]. This may either represent a decreased size of the follicular pool or mimic an improved follicular development and reduced levels of ovarian sex steroids [66-68, 71]. Moreover, delta changes of most circulating sex steroids $\left(\mathrm{E}_{1}, \mathrm{E}_{1}-\mathrm{S}, \mathrm{E}_{2}, \mathrm{~T}\right.$, free-T, DHT), sex steroid precursors (DHEA, DHEA-S) and glucuronidated androgen metabolites (ADT-G, AD3G, and $\mathrm{AD} 17 \mathrm{G})$, as determined by mass spectrometry differed between the intervention groups. Differences in $E_{1}-S, E_{2}$, DHEA, free-T, and ADT-G held for bonferroni correction. Acupuncture reduced levels of $E_{1}, E_{1}-S, E_{2}$, DHEA, DHEA-S, 4-DIONE, $\mathrm{T}$, and free $\mathrm{T}$ from baseline to end of treatment [173]. This is in line with, and extends, our previous RCT where several of these steroids were reduced [166]. Also here the clinical data is in line with the experimental data, where acupuncture with low-frequency electrical stimulation reduced levels of testosterone in DHT-induced PCOS rats [156]. The enhanced effect regarding both ovulation and sex steroids may be explained by increased number of treatments, more than 20 treatments, compared to the previous study comparing 14 treatments with acupuncture and exercise, as our animal studies infer dose-responsive effects $[166,173,175$, 176].

5.1. Gap in Knowledge. The present studies on menstrual and ovulation frequency have limited sample size and lack longitudinal followup for more than 16 weeks. It is also of importance to describe the most effective treatment regimen including maintenance treatment.

Treatment of first choice for ovulation induction in women with PCOS attempting to conceive is lifestyle interventions [177] and thereafter clomiphene citrate (CC) [178]. Ovarian hyperstimulation, multiple gestations, and spontaneous abortions ( $20 \%$ instead of the normal $12-15 \%)$ belong to the adverse effects of CC stimulation, although rare $[178,179]$. Approximate $20 \%$ of PCOS women are designated to be CC resistant $[180,181]$ and if CC fails, gonadotropin (FSH) therapy or laparoscopic ovarian surgery is considered as further treatment. The efficacy of gonadotropins is a $70 \%$ ovulation rate and a $20 \%$ pregnancy rate [178], but the treatment is costly and requires intensive ovarian monitoring [182]. Laparoscopic ovarian surgery (LOS), such as ovarian drilling by electrocautery or laser, has a pregnancy rate between $25-51 \%$ and a live birth between 24-44\% [183]. However, these more invasive treatments are associated with side-effects such as adherence. Other used treatments for ovulation induction are considered in more detail in other review articles such as the ESHRE/ARSM sponsored PCOS consensus report from 2007 [178]. The earlier described acupuncture studies show improvement of menstrual and ovulatory function and may therefore also improve pregnancy rate in women with PCOS, either alone or in combination with traditional treatment $[166,171,173]$.

5.2. Gap in Knowledge. Previous studies indicate that acupuncture induces ovulation and thus may lead to pregnancy in women with PCOS $[166,173]$. However, none of these trials were designed to investigate pregnancy or live birth. This gap in knowledge is addressed in an ongoing, multicenter, headto-head RCT (ClinicalTrials.gov: NCT01573858) in China. This trial tests the following hypotheses in anovulatory women with PCOS: (1) true acupuncture and CC are more likely to result in ovulation and live birth than control acupuncture and CC, (2) control acupuncture and CC are more likely to result in ovulation than true acupuncture and placebo CC, and (3) true acupuncture and placebo CC are more likely to result in live birth than control acupuncture and placebo CC.

5.3. Acupuncture on Neuroendocrine Function in PCOS. To elucidate possible explanations for the effect of acupuncture on ovulation in women with PCOS and DHT-induced PCOS rats studies measuring LH pulsatility and experimental studies exploring other neuroendocrine functions have been conducted with varying results $[156,173,184]$.

In the rat, the highest density of GnRH neurons is located in the rostral medium septum (MS), diagonal band of Broca, and medial preoptic area (MPO) [185]. Most GnRH neurons send projections via mediobasal hypothalamus down to the median eminence where GnRH is released into pituitary portal blood $[186,187]$. In DHT-induced PCOS rats, there seem to be more GnRH-immunoreactive (GnRH-ir) cells in the MPO and horizontal limb of the diagonal band (HDB) than in control rats [184]. Additionally, compared to controls, the PCOS rats displayed increased levels of hypothalamic functionally active androgen receptor (AR) and AR-ir cells in the MPO as determined by western blot and immunohistochemistry (IHC). This implies that androgens may have a regulatory effect on the $\mathrm{GnRH}$ neurons. Moreover, the increased levels of GnRH-ir cells and AR in hypothalamus were reduced after electroacupuncture treatment [184]. Estrogen receptor $\beta$ has previously been shown to be colocalized with GnRH neurons, thereby indicating a direct 
action of estrogens on GnRH regulation [188]. It has also demonstrated a colocalization of AR and GnRH neurons that further strengthens the hypothesis of a direct androgenic regulatory control on GnRH neurons [184]. Hence, we have indications that both the GnRH abnormalities and the effect of electroacupuncture could be mediated via the $A R$ in hypothalamus. Moreover, previous experiments have demonstrated that levels of circulating estradiol are not altered in the DHT-induced rat PCOS model, which further supports the conclusion that this is an androgenic effect [22].

Although the arcuate nucleus is considered to be the principal location of the GnRH pulse generator in the rat brain, the preoptic area regulates the $\mathrm{GnRH}$ secretion surge controlling the preovulatory LH surge $[132,189]$ making the findings in MPO even more interesting. Administration of androgens prenatally has previously been shown to increase LH pulsatility, without affecting pituitary responsiveness to $\mathrm{GnRH}$, and to abolish the estrogen-induced LH surge, which is indicative of acceleration in the GnRH pulse generator. A contemporary reduction of estradiol-induced progesterone receptor (PR) expression in the preoptic area was then considered as evidence of how androgens could mediate this effect [190]. 4-day administration of androgens to adult rats produced similar results on the LH surge and PR expression but with the contrast of an instead decreased LH and possibly GnRH secretion, similar to the male response [191, 192] and in oppose to human PCOS. These results are indicative of a programming effect (defect) of androgens during prenatal development that is different from the direct effects of hyperandrogenemia in adult life. Since in the DHT-induced PCOS model, rats are continuous exposed to androgens from day 21 until adult life, it is possible that they also have reduced GnRH secretion, with abolished GnRH/LH surges [191, 192]. One might therefore speculate that restoration of the GnRH and LH surge by effects on the androgen receptor in the MPO could be at least part of the mechanism behind the improved estrous cyclicity after electroacupuncture. A succeeding study could not confirm the affected hypothalamic GnRH and AR expression; however, these measurements were made at mRNA level [156]. This could mean that the effect is related to posttranslational events rather than gene expression changes. However, no measurements of LH pulsatility have been performed in the DHT-induced rat PCOS model, either basally or after electroacupuncture, to confirm a physiological effect.

The hypothesis that the higher ovulation frequency by acupuncture in women with PCOS is due to restoration of gonadotropin secretion was tested in the recent RCT [173]. However, none of the LH pulsatility measures were affected by acupuncture treatment twice a week during 3 months. The major effect accompanying the higher ovulation frequency and reduced circulating inhibin B levels in the acupuncture group was the general decrease in circulating sex steroids, androgen precursors, and glucuronidated androgen metabolites after treatment, pointing towards an effect at ovarian and adrenal levels. However, it does not exclude involvement of central control mechanisms [173].

In an earlier RCT comparing sham and true acupuncture in PCOS women the LH:FSH ratio was decreased in both groups together with rather high ovulation frequencies [171].
The lack of effect on LH pulsatility in the latest RCT [173] may be due to the sampling timing in the menstrual cycle, which could be a confounding factor $[44,193,194]$. The majority of endpoint overnight blood sampling was performed during cycle day 8-10 (mid to late follicular phase). It is possible that an effect might have been seen if blood samplings were instead performed in early follicular phase [173].

\section{Discussion}

The viscous circle of PCOS features aggravating each other may be driven by androgens, insulin, or other factors but must be broken to improve the health status of women with PCOS. Although pharmacological treatment may be effective, they are also associated with negative side-effects [97]. This review addresses acupuncture as a potential treatment option for reproductive and endocrine disturbances in women with PCOS. Several clinical and animal experimental studies indicate that acupuncture is beneficial for ovulatory dysfunction in PCOS. This is also related to decreased levels of sex steroids and possibly inhibin B. Although the clinical data does not support changes in $\mathrm{LH}$ pulsatility/secretion pattern as a possible mediator for this effect [82], there is strong evidence of central components that probably involve both opioid and sympathetic activities, an effect that may be mediated via the androgen receptor. However, the causality of changes in ovulation and sex steroids is difficult to determine. The reduction of androgen levels by normalization of intrinsic ovarian aberrations may calm the exaggerated follicular growth, restore the follicle maturation processes, and hence lead to ovulation [12]. It could also be the other way around that improved ovulation, possibly caused by external factors, restoring follicular growth and/or aberrations and thereby reducing androgen levels due to the lower pool and/or activity of androgen producing cells [32].

Improved menstrual and ovulatory patterns are indeed beneficial, both for women not trying and women who are attempting to conceive. Further studies are needed to investigate whether acupuncture improves pregnancy and live birth rate in women with PCOS.

For the purpose of implementing acupuncture in the conventional treatment strategy, though, it is also of importance to compare it with the first-line pharmaceutical options. This is important for the support and sanction of acupuncture as a treatment method. To further investigate the underlying mechanisms of the effect of acupuncture may also be supportive in the search for other possible alternative treatments, including pharmacological.

\section{References}

[1] B. O. Yildiz, G. Bozdag, Z. Yapici, I. Esinler, and H. Yarali, "Prevalence, phenotype and cardiometabolic risk of polycystic ovary syndrome under different diagnostic criteria," Human Reproduction, vol. 27, pp. 3067-3073, 2012.

[2] W. A. March, V. M. Moore, K. J. Willson, D. I. W. Phillips, R. J. Norman, and M. J. Davies, "The prevalence of polycystic ovary syndrome in a community sample assessed under contrasting 
diagnostic criteria," Human Reproduction, vol. 25, no. 2, pp. 544-551, 2010.

[3] R. A. Wild, E. Carmina, E. Diamanti-Kandarakis et al., "Assessment of cardiovascular risk and prevention of cardiovascular disease in women with the polycystic ovary syndrome: a consensus statement by the androgen excess and polycystic ovary syndrome (AE-PCOS) society," The Journal of Clinical Endocrinology and Metabolism, vol. 95, no. 5, pp. 2038-2049, 2010.

[4] T. Sathyapalan and S. L. Atkin, "Recent advances in cardiovascular aspects of polycystic ovary syndrome," European Journal of Endocrinology, vol. 166, no. 4, pp. 575-583, 2012.

[5] (NIH) NIoH, Evidence-Based Methodology Workshop on Polycystic Ovary Syndrome, 2012.

[6] T. Sir-Petermann, E. Codner, V. Pérez et al., "Metabolic and reproductive features before and during puberty in daughters of women with polycystic ovary syndrome," The Journal of Clinical Endocrinology and Metabolism, vol. 94, no. 6, pp. 1923-1930, 2009.

[7] S. Franks, "Adult polycystic ovary syndrome begins in childhood," Best Practice and Research, vol. 16, no. 2, pp. 263-272, 2002.

[8] S. F. Witchel, "Puberty and polycystic ovary syndrome," Molecular and Cellular Endocrinology, vol. 254-255, pp. 146-153, 2006.

[9] N. K. Stepto, S. Cassar, A. E. Joham et al., "Women with polycystic ovary syndrome have intrinsic insulin resistance on euglycaemic-hyperinsulaemic clamp," Human Reproduction, vol. 28, no. 3, pp. 777-784, 2013.

[10] R. Azziz, E. Carmina, D. Dewailly et al., "Position statement: criteria for defining polycystic ovary syndrome as a predominantly hyperandrogenic syndrome: an androgen excess society guideline," The Journal of Clinical Endocrinology and Metabolism, vol. 91, no. 11, pp. 4237-4245, 2006.

[11] E. Stener-Victorin, G. Holm, F. Labrie, L. Nilsson, P. O. Janson, and C. Ohlsson, "Are there any sensitive and specific sex steroid markers for polycystic ovary syndrome?" The Journal of Clinical Endocrinology and Metabolism, vol. 95, no. 2, pp. 810-819, 2010.

[12] V. Nisenblat and R. J. Norman, "Androgens and polycystic ovary syndrome," Current Opinion in Endocrinology, Diabetes and Obesity, vol. 16, no. 3, pp. 224-231, 2009.

[13] R. Pasquali and F. Casimirri, "The impact of obesity on hyperandrogenism and polycystic ovary syndrome in premenopausal women," Clinical Endocrinology, vol. 39, no. 1, pp. 1-16, 1993.

[14] T. D. Pache, S. Chadha, L. J. G. Gooren et al., "Ovarian morphology in long-term androgen-treated female to male transsexuals. A human mode for the study of polycystic ovarian syndrome?" Histopathology, vol. 19, no. 5, pp. 445-452, 1991.

[15] J. M. H. Elbers, E. J. Giltay, T. Teerlink et al., "Effects of sex steroids on components of the insulin resistance syndrome in transsexual subjects," Clinical Endocrinology, vol. 58, no. 5, pp. 562-571, 2003.

[16] S. Franks, "Do animal models of polycystic ovary syndrome help to understand its pathogenesis and management? Yes, but their limitations should be recognized," Endocrinology, vol. 150, no. 9, pp. 3983-3985, 2009.

[17] D. H. Abbott, A. F. Tarantal, and D. A. Dumesic, "Fetal, infant, adolescent and adult phenotypes of polycystic ovary syndrome in prenatally androgenized female rhesus monkeys," American Journal of Primatology, vol. 71, no. 9, pp. 776-784, 2009.
[18] M. Manikkam, R. C. Thompson, C. Herkimer et al., "Developmental programming: impact of prenatal testosterone excess on pre- and postnatal gonadotropin regulation in sheep," Biology of Reproduction, vol. 78, no. 4, pp. 648-660, 2008.

[19] K. Hogg, J. M. Young, E. M. Oliver, C. J. Souza, A. S. McNeilly, and W. C. Duncan, "Enhanced thecal androgen production is prenatally programmed in an ovine model of polycystic ovary syndrome," Endocrinology, vol. 153, no. 1, pp. 450-461, 2012.

[20] T. Sir-Petermann, M. Maliqueo, B. Angel, H. E. Lara, F. PërezBravo, and S. E. Recabarren, "Maternal serum androgens in pregnant women with polycystic ovarian syndrome: possible implications in prenatal androgenization," Human Reproduction, vol. 17, no. 10, pp. 2573-2579, 2002.

[21] J. A. Barry, A. R. Kay, R. Navaratnarajah et al., "Umbilical vein testosterone in female infants born to mothers with polycystic ovary syndrome is elevated to male levels," Journal of Obstetrics and Gynaecology, vol. 30, no. 5, pp. 444-446, 2010.

[22] L. Mannerås, S. Cajander, A. Holmäng et al., "A new rat model exhibiting both ovarian and metabolic characteristics of polycystic ovary syndrome," Endocrinology, vol. 148, no. 8, pp. 37813791, 2007.

[23] E. Stener-Victorin, K. Ploj, B.-M. Larsson, and A. Holmäng, "Rats with steroid-induced polycystic ovaries develop hypertension and increased sympathetic nervous system activity," Reproductive Biology and Endocrinology, vol. 3, article 44, 2005.

[24] E. L. van Houten, P. Kramer, A. McLuskey et al., "Reproductive and metabolic phenotype of a mouse model of PCOS," Endocrinology, vol. 153, pp. 2861-2869, 2012.

[25] B. C. J. M. Fauser, B. C. Tarlatzis, R. W. Rebar et al., "Consensus on women's health aspects of polycystic ovary syndrome (PCOS): The Amsterdam ESHRE/ASRM-Sponsored 3rd PCOS Consensus Workshop Group," Fertility and Sterility, vol. 97, no. 1, pp. 28.e25-38.e25, 2012.

[26] A. N. Schüring, N. Schulte, B. Sonntag, and L. Kiesel, "Androgens and insulin-two key players in polycystic ovary syndrome: recent concepts in the pathophysiology and genetics of polycystic ovary syndrome," Gynakologisch-Geburtshilfliche Rundschau, vol. 48, no. 1, pp. 9-15, 2008.

[27] S. S. Lim, R. J. Norman, M. J. Davies, and L. J. Moran, “The effect of obesity on polycystic ovary syndrome: a systematic review and meta-analysis," Obesity Reviews, vol. 14, no. 2, pp. 95-109, 2012.

[28] S. Franks, M. I. McCarthy, K. Hardy et al., "Development of polycystic ovary syndrome: involvement of genetic and environmental factors," International Journal of Andrology, vol. 29, no. 1, pp. 278-285, 2006.

[29] D. H. Abbott, D. A. Dumesic, and S. Franks, "Developmental origin of polycystic ovary syndrome-a hypothesis," Journal of Endocrinology, vol. 174, no. 1, pp. 1-5, 2002.

[30] Y. B. Sverrisdóttir, T. Mogren, J. Kataoka, P. O. Janson, and E. Stener-Victorin, "Is polycystic ovary syndrome associated with high sympathetic nerve activity and size at birth?" American Journal of Physiology, vol. 294, no. 3, pp. E576-E581, 2008.

[31] A. H. Balen, "Hypersecretion of luteinizing hormone and the polycystic ovary syndrome," Human Reproduction, vol. 8, supplement 2, pp. 123-128, 1993.

[32] C. M. Burt Solorzano, J. P. Beller, M. Y. Abshire, J. S. Collins, C. R. McCartney, and J. C. Marshall, "Neuroendocrine dysfunction in polycystic ovary syndrome," Steroids, vol. 77, no. 4, pp. 332-337, 2012. 
[33] S. K. Blank, C. R. McCartney, and J. C. Marshall, “The origins and sequelae of abnormal neuroendocrine function in polycystic ovary syndrome," Human Reproduction Update, vol. 12, no. 4, pp. 351-361, 2006.

[34] S. K. Blank, C. R. McCartney, K. D. Helm, and J. C. Marshall, "Neuroendocrine effects of androgens in adult polycystic ovary syndrome and female puberty," Seminars in Reproductive Medicine, vol. 25, no. 5, pp. 352-359, 2007.

[35] R. Rebar, H. L. Judd, S. S. Yen, J. Rakoff, G. Vandenberg, and F. Naftolin, "Characterization of the inappropriate gonadotropin secretion in polycystic ovary syndrome," Journal of Clinical Investigation, vol. 57, no. 5, pp. 1320-1329, 1976.

[36] A. Arroyo, G. A. Laughlin, A. J. Morales, and S. S. C. Yen, "Inappropriate gonadotropin secretion in polycystic ovary syndrome: influence of adiposity," The Journal of Clinical Endocrinology and Metabolism, vol. 82, no. 11, pp. 3728-3733, 1997.

[37] J. Waldstreicher, N. F. Santoro, J. E. Hall, M. Filicori, and W. F. Crowley Jr., "Hyperfunction of the hypothalamic-pituitary axis in women with polycystic ovarian disease: indirect evidence for partial gonadotroph desensitization," The Journal of Clinical Endocrinology and Metabolism, vol. 66, no. 1, pp. 165-172, 1988.

[38] A. P. Cheung, J. K. H. Lu, and R. J. Chang, "Pulsatile gonadotrophin secretion in women with polycystic ovary syndrome after gonadotrophin-releasing hormone agonist treatment," Human Reproduction, vol. 12, no. 6, pp. 1156-1164, 1997.

[39] K. Patel, M. S. Coffler, M. H. Dahan, P. J. Malcom, R. Deutsch, and R. J. Chang, "Relationship of GnRH-stimulated LH release to episodic LH secretion and baseline endocrine-metabolic measures in women with polycystic ovary syndrome," Clinical Endocrinology, vol. 60, no. 1, pp. 67-74, 2004.

[40] F. J. Hayes, A. E. Taylor, K. A. Martin, and J. E. Hall, "Use of a gonadotropin-releasing hormone antagonist as a physiologic probe in polycystic ovary syndrome: assessment of neuroendocrine and androgen dynamics," The Journal of Clinical Endocrinology and Metabolism, vol. 83, no. 7, pp. 2343-2349, 1998.

[41] C. L. Pastor, M. L. Griffin-Korf, J. A. Aloi, W. S. Evans, and J. C. Marshall, "Polycystic ovary syndrome: evidence for reduced sensitivity of the gonadotropin-releasing hormone pulse generator to inhibition by estradiol and progesterone," The Journal of Clinical Endocrinology and Metabolism, vol. 83, no. 2, pp. 582590, 1998.

[42] C. A. Eagleson, M. B. Gingrich, C. L. Pastor et al., "Polycystic ovarian syndrome: evidence that flutamide restores sensitivity of the gonadotropin-releasing hormone pulse generator to inhibition by estradiol and progesterone," The Journal of Clinical Endocrinology and Metabolism, vol. 85, no. 11, pp. 4047-4052, 2000.

[43] T. L. Daniels and S. L. Berga, "Resistance of gonadotropin releasing hormone drive to sex steroid- induced suppression in hyperandrogenic anovulation," The Journal of Clinical Endocrinology and Metabolism, vol. 82, no. 12, pp. 4179-4183, 1997.

[44] A. D. Genazzani, C. Strucchi, M. Luisi et al., "Metformin administration modulates neurosteroids secretion in non-obese amenorrhoic patients with polycystic ovary syndrome," Gynecological Endocrinology, vol. 22, no. 1, pp. 36-43, 2006.

[45] S. K. Blank, C. R. McCartney, S. Chhabra et al., "Modulation of gonadotropin-releasing hormone pulse generator sensitivity to progesterone inhibition in hyperandrogenic adolescent girlsimplications for regulation of pubertal maturation," The Journal of Clinical Endocrinology and Metabolism, vol. 94, no. 7, pp. 2360-2366, 2009.

[46] F. Tosi, C. Negri, F. Perrone et al., "Hyperinsulinemia amplifies $\mathrm{GnRH}$ agonist stimulated ovarian steroid secretion in women with polycystic ovary syndrome," The Journal of Clinical Endocrinology and Metabolism, vol. 97, pp. 1712-1719, 2012.

[47] S. Jonard and D. Dewailly, "The follicular excess in polycystic ovaries, due to intra-ovarian hyperandrogenism, may be the main culprit for the follicular arrest," Human Reproduction Update, vol. 10, no. 2, pp. 107-117, 2004.

[48] S. Franks, J. Stark, and K. Hardy, "Follicle dynamics and anovulation in polycystic ovary syndrome," Human Reproduction Update, vol. 14, no. 4, pp. 367-378, 2008.

[49] S. G. Millier, P. F. Whitelaw, and C. D. Smyth, "Follicular oestrogen synthesis: the 'two-cell, two-gonadotrophin' model revisited," Molecular and Cellular Endocrinology, vol. 100, no. 1-2, pp. 51-54, 1994.

[50] D. A. Magoffin, “Ovarian theca cell," International Journal of Biochemistry \& Cell Biology, vol. 37, no. 7, pp. 1344-1349, 2005.

[51] V. L. Nelson, R. S. Legro, J. F. Strauss III, and J. M. McAllister, "Augmented androgen production is a stable steroidogenic phenotype of propagated theca cells from polycystic ovaries," Molecular Endocrinology, vol. 13, no. 6, pp. 946-957, 1999.

[52] B. Almog, F. Shehata, S. Suissa et al., "Age-related normograms of serum antimüllerian hormone levels in a population of infertile women: a multicenter study," Fertility and Sterility, vol. 95, no. 7, pp. 2359.e1-2363.e1, 2011.

[53] D. B. Seifer, V. L. Baker, and B. Leader, "Age-specific serum anti-Müllerian hormone values for 17,120 women presenting to fertility centers within the United States," Fertility and Sterility, vol. 95, no. 2, pp. 747-750, 2011.

[54] A. L. L. Durlinger, M. J. G. Gruijters, P. Kramer et al., "AntiMüllerian hormone attenuates the effects of FSH on follicle development in the mouse ovary," Endocrinology, vol. 142, no. 11, pp. 4891-4899, 2001.

[55] A. L. L. Durlinger, P. Kramer, B. Karels et al., "Control of primordial follicle recruitment by anti-mullerian hormone in the mouse ovary," Endocrinology, vol. 140, no. 12, pp. 5789-5796, 1999.

[56] A. L. L. Durlinger, M. J. G. Gruijters, P. Kramer et al., "AntiMüllerian hormone inhibits initiation of primordial follicle growth in the mouse ovary," Endocrinology, vol. 143, no. 3, pp. 1076-1084, 2002.

[57] S. A. Stubbs, K. Hardy, P. Da Silva-Buttkus et al., "Anti-müllerian hormone protein expression is reduced during the initial stages of follicle development in human polycystic ovaries," The Journal of Clinical Endocrinology and Metabolism, vol. 90, no. 10, pp. 5536-5543, 2005.

[58] L. J. Moran, M. Noakes, P. M. Clifton, and R. J. Norman, "The use of anti-müllerian hormone in predicting menstrual response after weight loss in overweight women with polycystic ovary syndrome," The Journal of Clinical Endocrinology and Metabolism, vol. 92, no. 10, pp. 3796-3802, 2007.

[59] R. L. Thomson, J. D. Buckley, L. J. Moran et al., "The effect of weight loss on anti-Müllerian hormone levels in overweight and obese women with polycystic ovary syndrome and reproductive impairment," Human Reproduction, vol. 24, no. 8, pp. 1976-1981, 2009. 
[60] J. Franasiak, S. L. Young, C. D. Williams, and L. M. Pastore, "Longitudinal anti-mullerian hormone in women with polycystic ovary syndrome: an acupuncture randomized clinical trial," Evidence-Based Complementary and Alternative Medicine, vol. 2012, Article ID 973712, 7 pages, 2012.

[61] M. E. Fallat, Y. Siow, M. Marra, C. Cook, and A. Carrillo, "Mullerian-inhibiting substance in follicular fluid and serum: a comparison of patients with tubal factor infertility, polycystic ovary syndrome, and endometriosis," Fertility and Sterility, vol. 67, no. 5, pp. 962-965, 1997.

[62] C. L. Cook, Y. Siow, A. G. Brenner, and M. E. Fallat, "Relationship between serum müllerian-inhibiting substance and other reproductive hormones in untreated women with polycystic ovary syndrome and normal women," Fertility and Sterility, vol. 77, no. 1, pp. 141-146, 2002.

[63] A. Falbo, M. Rocca, T. Russo et al., "Serum and follicular antiMullerian hormone levels in women with polycystic ovary syndrome (PCOS) under metformin," Journal of Ovarian Research, vol. 3, no. 1, article 16, 2010.

[64] P. Pigny, E. Merlen, Y. Robert et al., "Elevated serum level of anti-mullerian hormone in patients with polycystic ovary syndrome: relationship to the ovarian follicle excess and to the follicular arrest," The Journal of Clinical Endocrinology and Metabolism, vol. 88, no. 12, pp. 5957-5962, 2003.

[65] N. Crisosto, T. Sir-Petermann, M. Greiner et al., "Testosteroneinduced downregulation of anti-Müllerian hormone expression in granulosa cells from small bovine follicles," Endocrine, vol. 36, no. 2, pp. 339-345, 2009.

[66] A. L. Chand, C. A. Harrison, and A. N. Shelling, "Inhibin and premature ovarian failure," Human Reproduction Update, vol. 16, no. 1, pp. 39-50, 2010.

[67] M. Torgac, A. Kokcu, M. B. Cetinkaya, T. Alper, and E. Malatyalioglu, "Do basal inhibin A and inhibin B levels have value in the diagnosis of polycystic ovary syndrome?" Gynecological Endocrinology, vol. 20, no. 6, pp. 322-326, 2005.

[68] M. C. Chu, E. Carmina, J. Wang, and R. A. Lobo, "Müllerianinhibiting substance reflects ovarian findings in women with polycystic ovary syndrome better than does inhibin B," Fertility and Sterility, vol. 84, no. 6, pp. 1685-1688, 2005.

[69] M. A. Rosencrantz, D. S. Wachs, M. S. Coffler, P. J. Malcom, M. Donohue, and R. J. Chang, "Comparison of inhibin B and estradiol responses to intravenous FSH in women with polycystic ovary syndrome and normal women," Human Reproduction, vol. 25, no. 1, pp. 198-203, 2010.

[70] D. S. Wachs, M. S. Coffler, P. J. Malcom, and R. J. Chang, "Comparison of follicle-stimulating-hormone-stimulated dimeric inhibin and estradiol responses as indicators of granulosa cell function in polycystic ovary syndrome and normal women," The Journal of Clinical Endocrinology and Metabolism, vol. 91, no. 8, pp. 2920-2925, 2006.

[71] C. K. Welt, A. E. Taylor, J. Fox, G. M. Messerlian, J. M. Adams, and A. L. Schneyer, "Follicular arrest in polycystic ovary syndrome is associated with deficient inhibin A and B biosynthesis," The Journal of Clinical Endocrinology and Metabolism, vol. 90, no. 10, pp. 5582-5587, 2005.

[72] H. W. R. Li, R. A. Anderson, W. S. B. Yeung, P. C. Ho, and E. H. Y. $\mathrm{Ng}$, "Evaluation of serum antimullerian hormone and inhibin $\mathrm{B}$ concentrations in the differential diagnosis of secondary oligoamenorrhea," Fertility and Sterility, vol. 96, no. 3, pp. 774779, 2011.
[73] G. M. Reaven, H. Lithell, and L. Landsberg, "Hypertension and associated metabolic abnormalities-the role of insulin resistance and the sympathoadrenal system," The New England Journal of Medicine, vol. 334, no. 6, pp. 374-381, 1996.

[74] A. Lansdown and D. Aled Rees, "The sympathetic nervous system in polycystic ovary syndrome: a novel therapeutic target?” Clinical Endocrinology, vol. 77, no. 6, pp. 791-801, 2012.

[75] M. Greiner, A. Paredes, V. Araya, and H. E. Lara, "Role of stress and sympathetic innervation in the development of polycystic ovary syndrome," Endocrine, vol. 28, no. 3, pp. 319-324, 2005.

[76] R. Sotomayor-Zárate, M. Dorfman, A. Paredes, and H. E. Lara, "Neonatal exposure to estradiol valerate programs ovarian sympathetic innervation and follicular development in the adult rat," Biology of Reproduction, vol. 78, no. 4, pp. 673-680, 2008.

[77] E. Stener-Victorin, E. Jedel, and L. Mannerås, "Acupuncture in polycystic ovary syndrome: current experimental and clinical evidence," Journal of Neuroendocrinology, vol. 20, no. 3, pp. 290298, 2008.

[78] C. Garcia-Rudaz, I. Armando, G. Levin, M. E. Escobar, and M. Barontini, "Peripheral catecholamine alterations in adolescents with polycystic ovary syndrome," Clinical Endocrinology, vol. 49, no. 2, pp. 221-228, 1998.

[79] U. Heider, I. Pedal, and K. Spanel-Borowski, "Increase in nerve fibers and loss of mast cells in polycystic and postmenopausal ovaries," Fertility and Sterility, vol. 75, no. 6, pp. 1141-1147, 2001.

[80] F. Giallauria, S. Palomba, F. Manguso et al., "Abnormal heart rate recovery after maximal cardiopulmonary exercise stress testing in young overweight women with polycystic ovary syndrome," Clinical Endocrinology, vol. 68, no. 1, pp. 88-93, 2008.

[81] A. Yildirir, F. Aybar, G. Kabakci, H. Yarali, and A. Oto, "Heart rate variability in young women with polycystic ovary syndrome," Annals of Noninvasive Electrocardiology, vol. 11, no. 4, pp. 306-312, 2006.

[82] G. Tekin, A. Tekin, E. B. Kilicarslan et al., "Altered autonomic neural control of the cardiovascular system in patients with polycystic ovary syndrome," International Journal of Cardiology, vol. 130, no. 1, pp. 49-55, 2008.

[83] G. A. Dissen, C. Garcia-Rudaz, A. Paredes, C. Mayer, A. Mayerhofer, and S. R. Ojeda, "Excessive ovarian production of nerve growth factor facilitates development of cystic ovarian morphology in mice and is a feature of polycystic ovarian syndrome in humans," Endocrinology, vol. 150, no. 6, pp. 29062914, 2009.

[84] K. A. Walters, C. M. Allan, and D. J. Handelsman, "Rodent models for human polycystic ovary syndrome," Biology of Reproduction, vol. 86, pp. 141-112, 2012.

[85] A. S. McNeilly and W. Colin Duncan, "Rodent models of polycystic ovary syndrome," Molecular and Cellular Endocrinology, vol. 373, no. 1-2, pp. 2-7, 2013.

[86] S. Franks, "Animal models and the developmental origins of polycystic ovary syndrome: increasing evidence for the role of androgens in programming reproductive and metabolic dysfunction," Endocrinology, vol. 153, pp. 2536-2538, 2012.

[87] J. Puurunen, T. Piltonen, P. Jaakkola, A. Ruokonen, L. MorinPapunen, and J. S. Tapanainen, "Adrenal androgen production capacity remains high up to menopause in women with polycystic ovary syndrome," The Journal of Clinical Endocrinology and Metabolism, vol. 94, no. 6, pp. 1973-1978, 2009. 
[88] F. Gonzalez, L. Chang, T. Horab, F. Z. Stanczyk, K. Crickard, and R. A. Lobo, "Adrenal dynamic responses to physiologic and pharmacologic adrenocorticotropic hormone stimulation before and after ovarian steroid modulation in women with polycystic ovary syndrome," Fertility and Sterility, vol. 71, no. 3, pp. 439-444, 1999.

[89] E. Diamanti-Kandarakis, A. G. Papavassiliou, S. A. Kandarakis, and G. P. Chrousos, "Pathophysiology and types of dyslipidemia in PCOS," Trends in Endocrinology and Metabolism, vol. 18, no. 7, pp. 280-285, 2007.

[90] R. Homburg, "Androgen circle of polycystic ovary syndrome," Human Reproduction, vol. 24, no. 7, pp. 1548-1555, 2009.

[91] L. Mannerås-Holm, H. Leonhardt, J. Kullberg et al., "Adipose tissue has aberrant morphology and function in PCOS: enlarged adipocytes and low serum adiponectin, but not circulating sex steroids, are strongly associated with insulin resistance," The Journal of Clinical Endocrinology and Metabolism, vol. 96, no. 2, pp. E304-E311, 2011.

[92] G. A. Dissen, C. Garcia-Rudaz, A. Paredes, C. Mayer, A. Mayerhofer, and S. R. Ojeda, "Excessive ovarian production of nerve growth factor facilitates development of cystic ovarian morphology in mice and is a feature of polycystic ovarian syndrome in humans," Endocrinology, vol. 150, no. 6, pp. 29062914, 2009.

[93] G. A. Dissen, H. E. Lara, V. Leyton et al., "Intraovarian excess of nerve growth factor increases androgen secretion and disrupts estrous cyclicity in the rat," Endocrinology, vol. 141, no. 3, pp. 1073-1082, 2000.

[94] J. M. Vink, S. Sadrzadeh, C. B. Lambalk, and D. I. Boomsma, "Heritability of polycystic ovary syndrome in a Dutch twinfamily study," The Journal of Clinical Endocrinology and Metabolism, vol. 91, no. 6, pp. 2100-2104, 2006.

[95] G. Kosova and M. Urbanek, "Genetics of the polycystic ovary syndrome," Molecular and Cellular Endocrinology, vol. 373, no. 1-2, pp. 29-38, 2013.

[96] Acupuncture NINCDPo, "Acupuncture," The Journal of the American Medical Association, vol. 280, pp. 1518-1524, 1998.

[97] C. M. Witt, D. Pach, B. Brinkhaus et al., "Safety of acupuncture: results of a prospective observational study with 229,230 patients and introduction of a medical information and consent form," Forschende Komplementarmedizin, vol. 16, no. 2, pp. 9197, 2009.

[98] H. Zhang, Z. Bian, and Z. Lin, "Are acupoints specific for diseases? A systematic review of the randomized controlled trials with sham acupuncture controls," Chinese Medicine, vol. 5, article 1, 2010.

[99] H. H. Moffet, "Sham acupuncture may be as efficacious as true acupuncture: a systematic review of clinical trials," Journal of Alternative and Complementary Medicine, vol. 15, no. 3, pp. 213216, 2009.

[100] G. Jansen, T. Lundeberg, J. Kjartansson, and U. E. Samuelson, "Acupuncture and sensory neuropeptides increase cutaneous blood flow in rats," Neuroscience Letters, vol. 97, no. 3, pp. 305309, 1989.

[101] A. Holmäng, K. Mimura, and P. Lönnroth, "Involuntary leg movements affect interstitial nutrient gradients and blood flow in rat skeletal muscle," Journal of Applied Physiology, vol. 92, no. 3, pp. 982-988, 2002.
[102] M. Blom, T. Lundeberg, I. Dawidson, and B. Angmar-Månsson, "Effects on local blood flux of acupuncture stimulation used to treat xerostomia in patients suffering from Sjögren's syndrome," Journal of Oral Rehabilitation, vol. 20, no. 5, pp. 541-548, 1993.

[103] M. Sandberg, T. Lundeberg, L.-G. Lindberg, and B. Gerdle, "Effects of acupuncture on skin and muscle blood flow in healthy subjects," European Journal of Applied Physiology, vol. 90, no. 1-2, pp. 114-119, 2003.

[104] I. Dawidson, B. Angmar-Månsson, M. Blom, E. Theodorsson, and T. Lundeberg, "The influence of sensory stimulation (acupuncture) on the release of neuropeptides in the saliva of healthy subjects," Life Sciences, vol. 63, no. 8, pp. 659-674, 1998.

[105] A. Sato, Y. Sato, M. Shimura, and S. Uchida, "Calcitonin generelated peptide produces skeletal muscle vasodilation following antidromic stimulation of unmyelinated afferents in the dorsal root in rats," Neuroscience Letters, vol. 283, no. 2, pp. 137-140, 2000.

[106] G. G. Zhang, C. Yu, W. Lee, L. Lao, K. Ren, and B. M. Berman, "Involvement of peripheral opioid mechanisms in electroacupuncture analgesia," Explore, vol. 1, no. 5, pp. 365-371, 2005.

[107] M. P. Kaufman, T. G. Waldrop, K. J. Rybicki, G. A. Ordway, and J. H. Mitchell, "Effects of static and rhythmic twitch contractions on the discharge of group III and IV muscle afferents," Cardiovascular Research, vol. 18, no. 11, pp. 663-668, 1984.

[108] H. Yamamoto, T. Kawada, A. Kamiya, S. Miyazaki, and M. Sugimachi, "Involvement of the mechanoreceptors in the sensory mechanisms of manual and electrical acupuncture," Autonomic Neuroscience, vol. 160, no. 1-2, pp. 27-31, 2011.

[109] J.-S. Han, "Physiology of acupuncture: review of thirty years of research," Journal of Alternative and Complementary Medicine, vol. 3, no. 1, pp. S-101-S-108, 1997.

[110] F. Kagitani, S. Uchida, H. Hotta, and Y. Aikawa, "Manual acupuncture needle stimulation of the rat hindlimb activates groups I, II, III and IV single afferent nerve fibers in the dorsal spinal roots," Japanese Journal of Physiology, vol. 55, no. 3, pp. 149-155, 2005.

[111] E. Stener-Victorin, R. Kobayashi, and M. Kurosawa, "Ovarian blood flow responses to electro-acupuncture stimulation at different frequencies and intensities in anaesthetized rats," Autonomic Neuroscience, vol. 108, no. 1-2, pp. 50-56, 2003.

[112] E. Stener-Victorin, S. Fujisawa, and M. Kurosawa, "Ovarian blood flow responses to electroacupuncture stimulation depend on estrous cycle and on site and frequency of stimulation in anesthetized rats," Journal of Applied Physiology, vol. 101, no. 1, pp. 84-91, 2006.

[113] B. Pomeranz and D. Chiu, "Naloxone blockade of acupuncture analgesia: endorphin implicated," Life Sciences, vol. 19, no. 11, pp. 1757-1762, 1976.

[114] D. J. Mayer, D. D. Price, and A. Rafii, "Antagonism of acupuncture analgesia in man by the narcotic antagonist naloxone," Brain Research, vol. 121, no. 2, pp. 368-372, 1977.

[115] R. S. S. Cheng and B. Pomeranz, "Electroacupuncture analgesia could be mediated by at least two pain-relieving mechanisms; endorphin and non-endorphin systems," Life Sciences, vol. 25, no. 23, pp. 1957-1962, 1979.

[116] T. Yao, S. Andersson, and P. Thoren, "Long-lasting cardiovascular depressor response following sciatic stimulation in 
spontaneously hypertensive rats. Evidence for the involvement of central endorphin and serotonin systems," Brain Research, vol. 244, no. 2, pp. 295-303, 1982.

[117] J. Fichna, A. Janecka, J. Costentin, and J.-C. Do Rego, "The endomorphin system and its evolving neurophysiological role," Pharmacological Reviews, vol. 59, no. 1, pp. 88-123, 2007.

[118] Z.-Q. Zhao, "Neural mechanism underlying acupuncture analgesia," Progress in Neurobiology, vol. 85, no. 4, pp. 355-375, 2008.

[119] H. Akil, S. J. Watson, E. Young, M. E. Lewis, H. Khachaturian, and J. M. Walker, "Endogenous opioids: biology and function," Annual Review of Neuroscience, vol. 7, pp. 223-255, 1984.

[120] S. Andersson and T. Lundeberg, "Acupuncture-from empiricism to science functional background to acupuncture effects in pain and disease," Medical Hypotheses, vol. 45, no. 3, pp. 271281, 1995.

[121] P. J. Jenkins and A. Grossman, "The control of the gonadotrophin releasing hormone pulse generator in relation to opioid and nutritional cues," Human Reproduction, vol. 8, supplement 2, pp. 154-161, 1993.

[122] T. Yao, S. Andersson, and P. Thoren, "Long-lasting cardiovascular depression induced by acupuncture-like stimulation of the sciatic nerve in unanaesthetized spontaneously hypertensive rats," Brain Research, vol. 240, no. 1, pp. 77-85, 1982.

[123] E. A. Young, J. Lewis, and H. Akil, "The preferential release of beta-endorphin from the anterior pituitary lobe by corticotropin releasing factor (CRF)," Peptides, vol. 7, no. 4, pp. 603$607,1986$.

[124] A. D. Eyvazzadeh, K. P. Pennington, R. Pop-Busui, M. Sowers, J.-K. Zubieta, and Y. R. Smith, "The role of the endogenous opioid system in polycystic ovary syndrome," Fertility and Sterility, vol. 92, no. 1, pp. 1-12, 2009.

[125] V. Clement-Jones, L. McLoughlin, S. Tomlin, G. M. Besser, L. H. Rees, and H. L. Wen, "Increased $\beta$-endorphin but not metenkephalin levels in human cerebrospinal fluid after acupuncture for recurrent pain," The Lancet, vol. 2, no. 8201, pp. 946-949, 1980.

[126] H.-J. Lee, J.-H. Lee, E.-O. Lee et al., "Substance P and betaendorphin mediate electro-acupuncture induced analgesia in mouse cancer pain model," Journal of Experimental \& Clinical Cancer Research, vol. 28, no. 1, article 102, 2009.

[127] S. Ahsin, S. Saleem, A. M. Bhatti, R. K. Iles, and M. Aslam, "Clinical and endocrinological changes after electro-acupuncture treatment in patients with osteoarthritis of the knee," Pain, vol. 147, no. 1-3, pp. 60-66, 2009.

[128] E. Stener-Victorin, E. Jedel, P. O. Janson, and Y. B. Sverrisdottir, "Low-frequency electroacupuncture and physical exercise decrease high muscle sympathetic nerve activity in polycystic ovary syndrome," American Journal of Physiology, vol. 297, no. 2, pp. R387-R395, 2009.

[129] T. Yao, S. Andersson, and P. Thoren, "Long-lasting cardiovascular depression induced by acupuncture-like stimulation of the sciatic nerve in unanaesthetized spontaneously hypertensive rats," Brain Research, vol. 240, no. 1, pp. 77-85, 1982.

[130] T. Yao, S. Andersson, and P. Thoren, "Long-lasting cardiovascular depressor response to somatic stimulation in spontaneously hypertensive rats," Acta Physiologica Scandinavica, vol. 111, no. 1, pp. 109-111, 1981.

[131] M. Ciechanowska, M. Łapot, K. Mateusiak, and F. Przekop, "Neuroendocrine regulation of GnRH release and expression of
GnRH and GnRH receptor genes in the hypothalamus-pituitary unit in different physiological states," Reproductive Biology, vol. 10, no. 2, pp. 85-124, 2010.

[132] F. Kimura and T. Funabashi, "Two subgroups of gonadotropinreleasing hormone neurons control gonadotropin secretion in rats," News in Physiological Sciences, vol. 13, no. 5, pp. 225-231, 1998.

[133] M. J. Smith and L. Jennes, "Neural signals that regulate GnRH neurones directly during the oestrous cycle," Reproduction, vol. 122, no. 1, pp. 1-10, 2001.

[134] P. Thoren, J. S. Floras, P. Hoffmann, and D. R. Seals, "Endorphins and exercise: physiological mechanisms and clinical implications," Medicine and Science in Sports and Exercise, vol. 22, no. 4, pp. 417-428, 1990.

[135] C. Rivier and S. Rivest, "Effect of stress on the activity of the hypothalamic-pituitary-gonadal axis: peripheral and central mechanisms," Biology of Reproduction, vol. 45, no. 4, pp. 523532, 1991.

[136] M. Xiao-Peng, L.-Y. Tan, Y. Yang et al., "Effect of electroacupuncture on substance $\mathrm{P}$, its receptor and corticotropinreleasing hormone in rats with irritable bowel syndrome," World Journal of Gastroenterology, vol. 15, no. 41, pp. 5211-5217, 2009.

[137] K. J. Sherman, D. C. Cherkin, L. Ichikawa et al., "Treatment expectations and preferences as predictors of outcome of acupuncture for chronic back pain," Spine, vol. 35, no. 15, pp. 1471-1477, 2010.

[138] J. Näslund, T. Lundeberg, I. Lund, and A. Sing, "Is placebo acupuncture what it is intended to be?" Evidence-Based Complementary and Alternative Medicine, vol. 2011, Article ID 932407, 5 pages, 2011.

[139] I. Lund, J. Näslund, and T. Lundeberg, "Minimal acupuncture is not a valid placebo control in randomised controlled trials of acupuncture: a physiologist's perspective," Chinese Medicine, vol. 4, article 1, 2009.

[140] F. Z. Zangeneh, A. Mohammadi, S. Ejtemaeimehr, M. M. Naghizadeh, and A. Fatemeh, "The role of opioid system and its interaction with sympathetic nervous system in the processing of polycystic ovary syndrome modeling in rat," Archives of Gynecology and Obstetrics, vol. 283, no. 4, pp. 885-892, 2011.

[141] F. A. Aleem and T. McIntosh, "Elevated plasma levels of $\beta$-endorphin in a group of women with polycystic ovarian disease," Fertility and Sterility, vol. 42, no. 5, pp. 686-689, 1984.

[142] J. Wortsman, W. B. Wehrenberg, J. R. Gavin III, and J. P. Allen, "Elevated levels of plasma $\beta$-endorphin and $\gamma 3$-melanocyte stimulating hormone in the polycystic ovary syndrome," Obstetrics and Gynecology, vol. 63, no. 5, pp. 630-634, 1984.

[143] F. Fruzzetti, C. Bersi, D. Parrini, C. Ricci, and A. R. Genazzani, "Effect of long-term naltrexone treatment on endocrine profile, clinical features, and insulin sensitivity in obese women with polycystic ovary syndrome," Fertility and Sterility, vol. 77, no. 5, pp. 936-944, 2002.

[144] M. I. Ahmed, A. J. Duleba, O. El Shahat, M. E. Ibrahim, and A. Salem, "Naltrexone treatment in clomiphene resistant women with polycystic ovary syndrome," Human Reproduction, vol. 23, no. 11, pp. 2564-2569, 2008.

[145] D. Hadžiomerović, B. Rabenbauer, and L. Wildt, "Normalization of hyperinsulinemia by chronic opioid receptor blockade in hyperandrogenemic women," Fertility and Sterility, vol. 86, no. 3, pp. 651-657, 2006. 
[146] C. Bo-Ying and Y. Jin, "Relationship between blood radioimmunoreactive beta-endorphin and hand skin temperature during the electro-acupuncture induction of ovulation," Acupuncture and Electro-Therapeutics Research, vol. 16, no. 1-2, pp. 1-5, 1991.

[147] A. Barria, V. Leyton, S. R. Ojeda, and H. E. Lara, "Ovarian steroidal response to gonadotropins and $\beta$-adrenergic stimulation is enhanced in polycystic ovary syndrome: role of sympathetic innervation," Endocrinology, vol. 133, no. 6, pp. 2696-2703, 1993.

[148] H. E. Lara, J. L. Ferruz, S. Luza, D. A. Bustamante, Y. Borges, and S. R. Ojeda, "Activation of ovarian sympathetic nerves in polycystic ovary syndrome," Endocrinology, vol. 133, no. 6, pp. 2690-2695, 1993.

[149] E. Stener-Victorin, T. Lundeberg, S. Cajander et al., "Steroidinduced polycystic ovaries in rats: effect of electro-acupuncture on concentrations of endothelin-1 and nerve growth factor (NGF), and expression of NGF mRNA in the ovaries, the adrenal glands, and the central nervous system," Reproductive Biology and Endocrinology, vol. 1, article 33, 2003.

[150] E. Stener-Victorin, T. Lundeberg, U. Waldenstrom et al., "Effects of electro-acupuncture on nerve growth factor and ovarian morphology in rats with experimentally induced polycystic ovaries," Biology of Reproduction, vol. 63, no. 5, pp. 1497-1503, 2000.

[151] L. Manni, A. Holmäng, T. Lundeberg, L. Aloe, and E. StenerVictorin, "Ovarian expression of alpha (1)- and beta (2)adrenoceptors and p75 neurotrophin receptors in rats with steroid-induced polycystic ovaries," Autonomic Neuroscience, vol. 118, no. 1-2, pp. 79-87, 2005.

[152] L. Manni, T. Lundeberg, A. Holmäng, L. Aloe, and E. StenerVictorin, "Effect of electro-acupuncture on ovarian expression of $\alpha(1)$ - and $\beta(2)$-adrenoceptors, and p75 neurotrophin receptors in rats with steroid-induced polycystic ovaries," Reproductive Biology and Endocrinology, vol. 3, article 21, 2005.

[153] L. Mannerås, S. Cajander, M. Lönn, and E. Stener-Victorin, "Acupuncture and exercise restore adipose tissue expression of sympathetic markers and improve ovarian morphology in rats with dihydrotestosterone-induced PCOS," American Journal of Physiology, vol. 296, no. 4, pp. R1124-R1131, 2009.

[154] E. Stener-Victorin, U. Waldenström, U. Tägnfors, T. Lundeberg, G. Lindstedt, and P. O. Janson, "Effects of electro-acupuncture on anovulation in women with polycystic ovary syndrome," Acta Obstetricia et Gynecologica Scandinavica, vol. 79, no. 3, pp. 180-188, 2000.

[155] X. Mo, D. Li, Y. Pu, G. Xi, X. Le, and Z. Fu, "Clinical studies on the mechanism for acupuncture stimulation of ovulation," Journal of traditional Chinese Medicine, vol. 13, no. 2, pp. 115119, 1993.

[156] Y. Feng, J. Johansson, R. Shao, L. M. Holm, H. Billig, and E. Stener-Victorin, "Electrical and manual acupuncture stimulation affect oestrous cyclicity and neuroendocrine function in an $5 \alpha$-dihydrotestosterone-induced rat polycystic ovary syndrome model," Experimental Physiology, vol. 97, no. 5, pp. 651-662, 2012.

[157] S. K. Hutchison, H. J. Teede, D. Rachoń, C. L. Harrison, B. J. Strauss, and N. K. Stepto, "Effect of exercise training on insulin sensitivity, mitochondria and computed tomography muscle attenuation in overweight women with and without polycystic ovary syndrome," Diabetologia, vol. 55, pp. 1424-1434, 2012.
[158] L. J. Moran, S. K. Hutchison, R. J. Norman, and H. J. Teede, "Lifestyle changes in women with polycystic ovary syndrome," Cochrane Database of Systematic Reviews, vol. 2, Article ID CD007506, 2011.

[159] J. R. Brawer, M. Munoz, and R. Farookhi, "Development of the polycystic ovarian condition (PCO) in the estradiol valeratetreated rat," Biology of Reproduction, vol. 35, no. 3, pp. 647-655, 1986.

[160] C. L. Harrison, C. B. Lombard, L. J. Moran, and H. J. Teede, "Exercise therapy in polycystic ovary syndrome: a systematic review," Human Reproduction Update, vol. 17, no. 2, pp. 171-183, 2011.

[161] C. L. Harrison, N. K. Stepto, S. K. Hutchison, and H. J. Teede, "The impact of intensified exercise training on insulin resistance and fitness in overweight and obese women with and without polycystic ovary syndrome," Clinical Endocrinology, vol. 76, no. 3, pp. 351-357, 2012.

[162] S. Palomba, A. Falbo, F. Giallauria et al., "Six weeks of structured exercise training and hypocaloric diet increases the probability of ovulation after clomiphene citrate in overweight and obese patients with polycystic ovary syndrome: a randomized controlled trial," Human Reproduction, vol. 25, no. 11, pp. 2783-2791, 2010.

[163] M.-M. Huber-Buchholz, D. G. P. Carey, and R. J. Norman, "Restoration of reproductive potential by lifestyle modification in obese polycystic ovary syndrome: role of insulin sensitivity and luteinizing hormone," The Journal of Clinical Endocrinology and Metabolism, vol. 84, no. 4, pp. 1470-1474, 1999.

[164] R. L. Thomson, J. D. Buckley, M. Noakes, P. M. Clifton, R. J. Norman, and G. D. Brinkworth, "The effect of a hypocaloric diet with and without exercise training on body composition, cardiometabolic risk profile, and reproductive function in overweight and obese women with polycystic ovary syndrome," The Journal of Clinical Endocrinology and Metabolism, vol. 93, no. 9, pp. 3373-3380, 2008.

[165] F. Giallauria, S. Palomba, L. Maresca et al., "Exercise training improves autonomic function and inflammatory pattern in women with polycystic ovary syndrome (PCOS)," Clinical Endocrinology, vol. 69, no. 5, pp. 792-798, 2008.

[166] E. Jedel, F. Labrie, A. Odén et al., "Impact of electro-acupuncture and physical exercise on hyperandrogenism and oligo/amenorrhea in women with polycystic ovary syndrome: a randomized controlled trial," American Journal of Physiology, vol. 300, no. 1, pp. E37-E45, 2011.

[167] M. A. Karimzadeh and M. Javedani, "An assessment of lifestyle modification versus medical treatment with clomiphene citrate, metformin, and clomiphene citrate-metformin in patients with polycystic ovary syndrome," Fertility and Sterility, vol. 94, no. 1, pp. 216-220, 2010.

[168] L. J. Moran, R. Pasquali, H. J. Teede, K. M. Hoeger, and R. J. Norman, "Treatment of obesity in polycystic ovary syndrome: a position statement of the Androgen Excess and Polycystic Ovary Syndrome Society," Fertility and Sterility, vol. 92, no. 6, pp. 1966-1982, 2009.

[169] D. S. Kiddy, D. Hamilton-Fairley, A. Bush et al., "Improvement in endocrine and ovarian function during dietary treatment of obese women with polycystic ovary syndrome," Clinical Endocrinology, vol. 36, no. 1, pp. 105-111, 1992.

[170] H. S. Randeva, K. C. Lewandowski, J. Drzewoski et al., "Exercise decreases plasma total homocysteine in overweight young 
women with polycystic ovary syndrome," The Journal of Clinical Endocrinology and Metabolism, vol. 87, no. 10, pp. 4496-4501, 2002.

[171] L. M. Pastore, C. D. Williams, J. Jenkins, and J. T. Patrie, “True and sham acupuncture produced similar frequency of ovulation and improved $\mathrm{LH}$ to FSH ratios in women with polycystic ovary syndrome," The Journal of Clinical Endocrinology and Metabolism, vol. 96, no. 10, pp. 3143-3150, 2011.

[172] E. Stener-Victorin, U. Waldenström, U. Tägnfors, T. Lundeberg, G. Lindstedt, and P. O. Janson, "Effects of electro-acupuncture on anovulation in women with polycystic ovary syndrome," Acta Obstetricia et Gynecologica Scandinavica, vol. 79, no. 3, pp. 180-188, 2000.

[173] J. Johansson, L. Redman, P. P. Veldhuis et al., "Acupuncture for ovulation induction in polycystic ovary syndrome: a randomized controlled trial," American Journal of Physiology Endocrinology and Metabolism, vol. 304, no. 9, pp. E934-E943, 2013.

[174] R. S. Legro, H. X. Barnhart, W. D. Schlaff et al., "Clomiphene, metformin, or both for infertility in the polycystic ovary syndrome," The New England Journal of Medicine, vol. 356, no. 6, pp. 551-566, 2007.

[175] L. Mannerås, I. H. Jonsdottir, A. Holmäng, M. Lönn, and E. Stener-Victorin, "Low-frequency electro-acupuncture and physical exercise improve metabolic disturbances and modulate gene expression in adipose tissue in rats with dihydrotestosterone-induced polycystic ovary syndrome," Endocrinology, vol. 149, no. 7, pp. 3559-3568, 2008.

[176] J. Johansson, Y. Feng, R. Shao, M. Lönn, H. Billig, and E. StenerVictorin, "Intense electroacupuncture normalizes insulin sensitivity, increases muscle GLUT4 content, and improves lipid profile in a rat model of polycystic ovary syndrome," American Journal of Physiology, vol. 299, no. 4, pp. E551-E559, 2010.

[177] H. J. Teede, M. L. Misso, A. A. Deeks et al., "Assessment and management of polycystic ovary syndrome: summary of an evidence-based guideline," The Medical Journal of Australia, vol. 195, no. 6, pp. S65-S112, 2011.

[178] B. C. Tarlatzis, B. C. J. M. Fauser, R. S. Legro et al., "Consensus on infertility treatment related to polycystic ovary syndrome," Human Reproduction, vol. 23, no. 3, pp. 462-477, 2008.

[179] R. Homburg, "Clomiphene citrate-end of an era? A minireview," Human Reproduction, vol. 20, no. 8, pp. 2043-2051, 2005.

[180] M. F. Costello, M. L. Misso, J. Wong et al., "The treatment of infertility in polycystic ovary syndrome: a brief update," Australian and New Zealand Journal of Obstetrics and Gynaecology, vol. 52, pp. 400-403, 2012.

[181] B. Imani, M. J. C. Eijkemans, E. R. te Velde, J. D. F. Habbema, and B. C. J. M. Fauser, "Predictors of patients remaining anovulatory during clomiphene citrate induction of ovulation in normogonadotropic oligoamenorrheic infertility," The Journal of Clinical Endocrinology and Metabolism, vol. 83, no. 7, pp. 2361-2365, 1998.

[182] S. Palomba, A. Falbo, and F. Zullo, "Management strategies for ovulation induction in women with polycystic ovary syndrome and known clomifene citrate resistance," Current Opinion in Obstetrics \& Gynecology, vol. 21, no. 6, pp. 465-473, 2009.

[183] C. Farquhar, R. J. Lilford, J. Marjoribanks, and P. Vandekerckhove, "Laparoscopic "drilling" by diathermy or laser for ovulation induction in anovulatory polycystic ovary syndrome," Cochrane Database of Systematic Reviews, no. 3, Article ID CD001122, 2007.

[184] Y. Feng, J. Johansson, R. Shao et al., "Hypothalamic neuroendocrine functions in rats with dihydrotestosterone-induced polycystic ovary syndrome: effects of low-frequency electroacupuncture," PLoS ONE, vol. 4, no. 8, Article ID e6638, 2009.

[185] J. W. Witkin, "Synchronized neuronal networks: the GnRH system," Microscopy Research and Technique, vol. 44, pp. 11-18, 1999.

[186] T. M. Plant, "A comparison of the neuroendocrine mechanisms underlying the initiation of the preovulatory LH surge in the human, Old World monkey and rodent," Frontiers in Neuroendocrinology, vol. 33, pp. 160-168, 2012.

[187] M.-C. Rogers, A.-J. Silverman, and M. J. Gibson, "Gonadotropin-releasing hormone axons target the median eminence: in vitro evidence for diffusible chemoattractive signals from the mediobasal hypothalamus," Endocrinology, vol. 138, no. 9, pp. 3956-3966, 1997.

[188] M. J. Skynner, J. A. Sim, and A. E. Herbison, "Detection of estrogen receptor $\alpha$ and $\beta$ messenger ribonucleic acids in adult gonadotropin-releasing hormone neurons," Endocrinology, vol. 140, no. 11, pp. 5195-5201, 1999.

[189] K.-I. Maeda, S. Adachi, K. Inoue, S. Ohkura, and H. Tsukamura, "Metastin/Kisspeptin and control of estrous cycle in rats," Reviews in Endocrine and Metabolic Disorders, vol. 8, no. 1, pp. 21-29, 2007.

[190] E. M. Foecking, M. Szabo, N. B. Schwartz, and J. E. Levine, "Neuroendocrine consequences of prenatal androgen exposure in the female rat: absence of luteinizing hormone surges, suppression of progesterone receptor gene expression, and acceleration of the gonadotropin-releasing hormone pulse generator," Biology of Reproduction, vol. 72, no. 6, pp. 1475-1483, 2005.

[191] E. M. Foecking and J. E. Levine, "Effects of experimental hyperandrogenemia on the female rat reproductive axis: suppression of progesterone-receptor messenger RNA expression in the brain and blockade of luteinizing hormone surges," Gender Medicine, vol. 2, no. 3, pp. 155-165, 2005.

[192] E. M. Foecking, M. A. McDevitt, M. Acosta-Martínez, T. H. Horton, and J. E. Levine, "Neuroendocrine consequences of androgen excess in female rodents," Hormones and Behavior, vol. 53, no. 5, pp. 673-692, 2008.

[193] W. G. Rossmanith, J. Keckstein, K. Spatzier, and C. Lauritzen, "The impact of ovarial laser surgery on the gonadotrophin secretion in women with polycystic ovarian disease," Clinical Endocrinology, vol. 34, no. 3, pp. 223-230, 1991.

[194] H. Martikainen, L. Ronnberg, A. Ruokonen, and A. Kauppila, "Gonadotropin pulsatility in a stimulated cycle: clomiphene citrate increases pulse amplitudes of both luteinizing hormone and follicle-stimulating hormone," Fertility and Sterility, vol. 56, no. 4, pp. 641-645, 1991. 


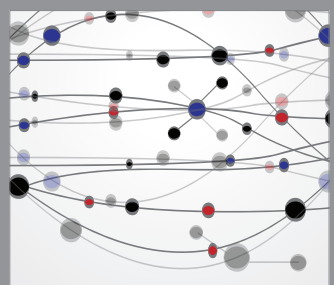

The Scientific World Journal
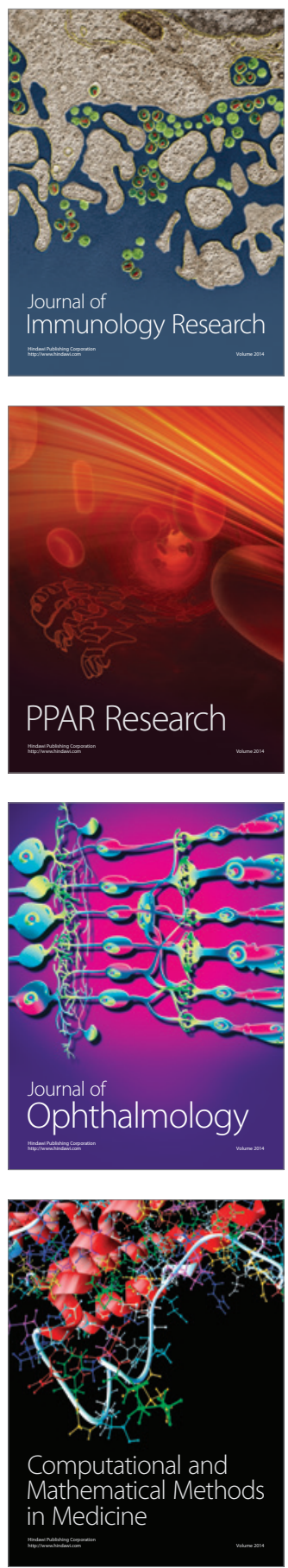

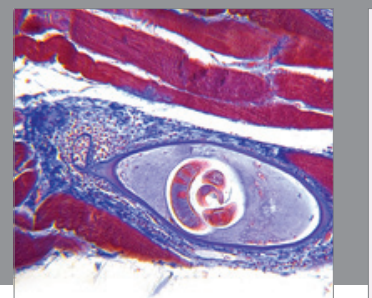

Gastroenterology

Research and Practice
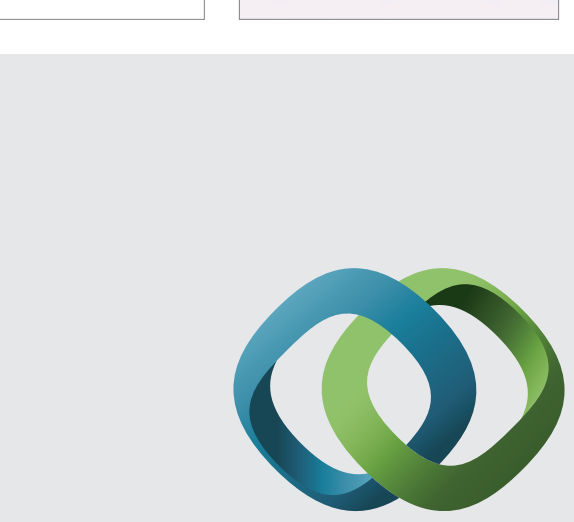

\section{Hindawi}

Submit your manuscripts at

http://www.hindawi.com
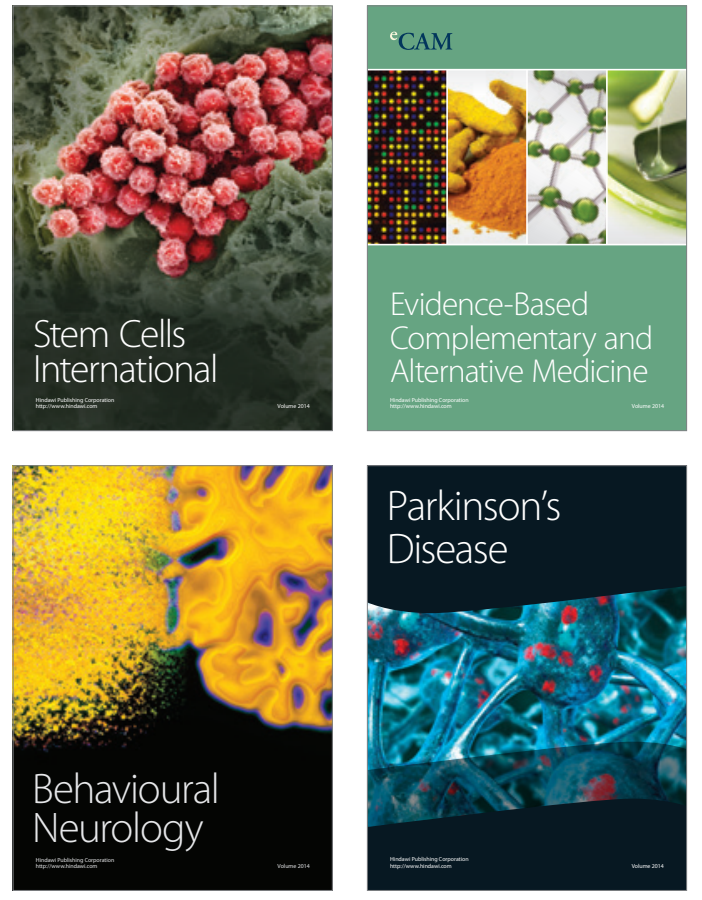
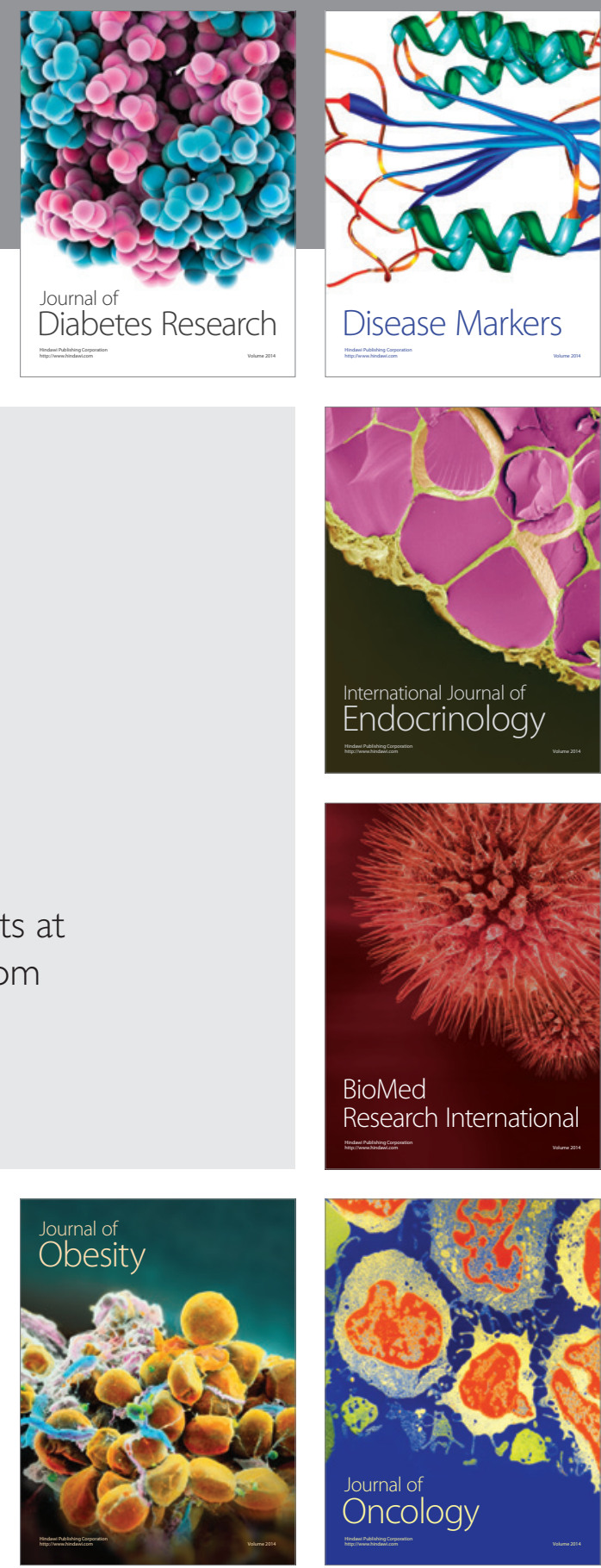

Disease Markers
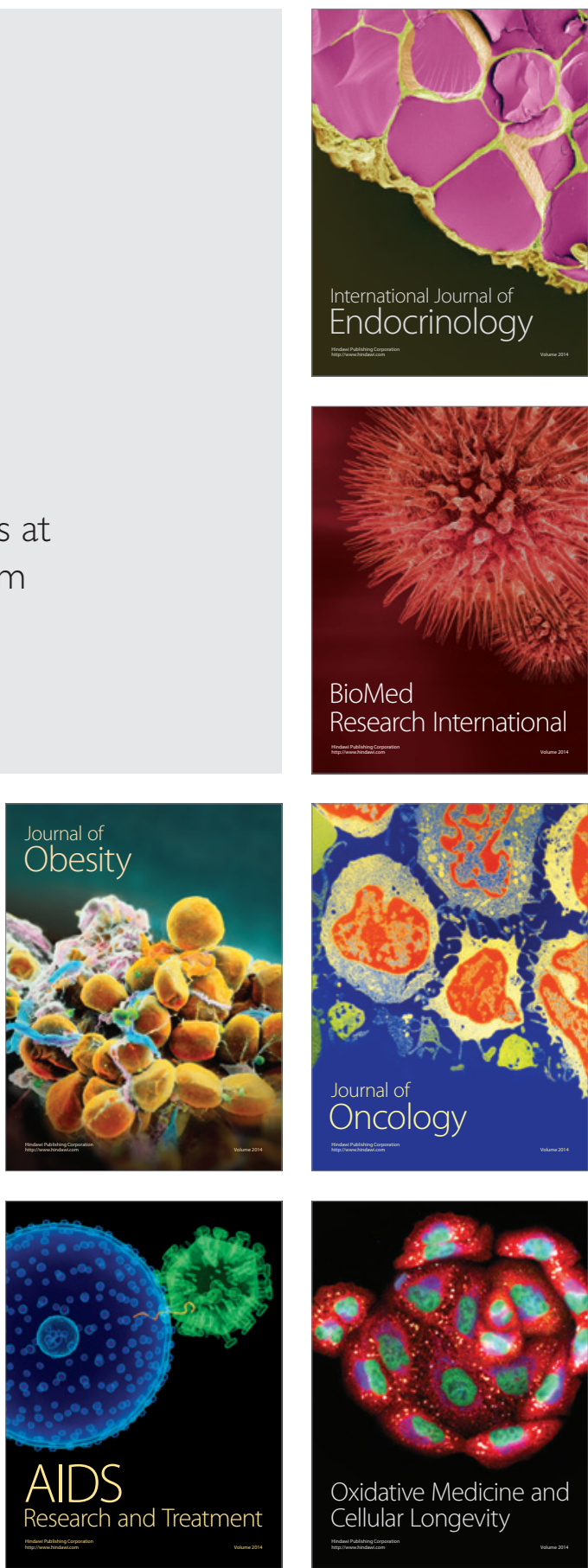